\title{
Article \\ Genomic Screening to Identify Food Trees Potentially Dispersed by Precolonial Indigenous Peoples
}

\author{
Monica Fahey ${ }^{1,2} \mathbb{D}$, Maurizio Rossetto ${ }^{2, *} \mathbb{C}$, Emilie Ens ${ }^{1}\left(\mathbb{D}\right.$ and Andrew Ford ${ }^{3}$ \\ 1 School of Natural Sciences, Faculty of Science and Engineering, Macquarie University, Sydney 2109, Australia; \\ monica.fahey@hdr.mq.edu.au (M.F.); emilie.ens@mq.edu.au (E.E.) \\ 2 Research Centre for Ecosystem Resilience, Royal Botanic Gardens, Australian Institute of Botanical Sciences, \\ Sydney 2000, Australia \\ 3 Formerly Tropical Forest Research Centre, CSIRO Land and Water, Atherton 4882, Australia; \\ andrewjford319@gmail.com \\ * Correspondence: maurizio.rossetto@botanicgardens.nsw.gov.au
}

Citation: Fahey, M.; Rossetto, M.; Ens, E.; Ford, A. Genomic Screening to Identify Food Trees Potentially Dispersed by Precolonial Indigenous Peoples. Genes 2022, 13, 476. https:// doi.org/10.3390/genes13030476

Academic Editors: Silvia Ghirotto, Chiara Barbieri, Linley Jesson and Wei Zhang

Received: 6 November 2021

Accepted: 3 March 2022

Published: 8 March 2022

Publisher's Note: MDPI stays neutral with regard to jurisdictional claims in published maps and institutional affiliations.

Copyright: (C) 2022 by the authors. Licensee MDPI, Basel, Switzerland. This article is an open access article distributed under the terms and conditions of the Creative Commons Attribution (CC BY) license (https:// creativecommons.org/licenses/by/ $4.0 /)$.

\begin{abstract}
Over millennia, Indigenous peoples have dispersed the propagules of non-crop plants through trade, seasonal migration or attending ceremonies; and potentially increased the geographic range or abundance of many food species around the world. Genomic data can be used to reconstruct these histories. However, it can be difficult to disentangle anthropogenic from non-anthropogenic dispersal in long-lived non-crop species. We developed a genomic workflow that can be used to screen out species that show patterns consistent with faunal dispersal or long-term isolation, and identify species that carry dispersal signals of putative human influence. We used genotyping-by-sequencing (DArTseq) and whole-plastid sequencing (SKIMseq) to identify nuclear and chloroplast Single Nucleotide Polymorphisms in east Australian rainforest trees (4 families, 7 genera, 15 species) with large $(>30 \mathrm{~mm})$ or small $(<30 \mathrm{~mm})$ edible fruit, either with or without a known history of use by Indigenous peoples. We employed standard population genetic analyses to test for four signals of dispersal using a limited and opportunistically acquired sample scheme. We expected different patterns for species that fall into one of three broadly described dispersal histories: (1) ongoing faunal dispersal, (2) post-megafauna isolation and (3) post-megafauna isolation followed by dispersal of putative human influence. We identified five large-fruited species that displayed strong population structure combined with signals of dispersal. We propose coalescent methods to investigate whether these genomic signals can be attributed to post-megafauna isolation and dispersal by Indigenous peoples.
\end{abstract}

Keywords: ethnobotany; anthropogenic dispersal; propagule dispersal; insipient domestication; Indigenous; fruit size; chloroplast genome; non-crop species; rainforest assembly; genomic screening

\section{Introduction}

Historical plant dispersal by Indigenous peoples has been recorded in many different parts of the world and there is a growing recognition that ancient Indigenous populations had a significant influence on the composition and distribution of ecosystems [1-8]. However, the literature is sparse, due to a lack of published research, loss of cultural knowledge following colonisation, or because historical and academic observations have been blind to the diversity of Indigenous planting practices [9-11]. Contemporary Indigenous knowledge holders and colonial-era observations indicate that Indigenous groups from around the world have cultivated, traded and dispersed useful or culturally significant plants across the landscape [10,12-17]. Whether intentional or incidental, these plant translocation events would have expanded the abundance and geographic range of many species, and many populations of so-called "wild" species are therefore likely to represent living cultural artefacts (for example [9,18-21]).

Molecular studies have sought to reconstruct the demographic history of food plant species to investigate the origins and processes of domestication [22-25]. These studies 
generally focus on crops that have been extensively genotyped and for which different cultivars are well-described (for example [26-30]). However, little work has been carried out on the human-mediated dispersal of non-crop species (although see [31-35]). This could be in the form of "assisted migration" which is the movement of a species outside it's natural range, "introduction" which is the establishment of new populations within a species' existing range and "reinforcement" which is the planting of propagules from one population into another [36]. Retracing propagule dispersal by pre-colonial Indigenous peoples (hereon referred to as 'Indigenous dispersal') is important for cultural resource recognition and management and can yield insights to the long-term evolutionary impacts of translocations that can be applied to restoration activities.

To advance this field of study, we advocate for the use of simple genomic tests to screen for species that are likely to yield signals of Indigenous dispersal. While there are likely thousands of plant species around the world that have known or unknown histories of Indigenous cultivation, not all these can be successfully uncovered by genomic studies. Even in cases where there is abundant ethnographic evidence of translocation, many species will not carry an easy to interpret genomic signal. For instance, the quantity of propagules dispersed by historical human activities, and the distances over which they were dispersed, may not have been sufficient to create genetic structure that can be readily discriminated from that created by non-human modes of dispersal (as appears to be the case with Camassia quamash, [33]).

Our study focuses on the rainforests of eastern Australia. Contemporary Indigenous knowledge and early colonial records reveal extensive movement of various rainforest trees for food cultivation, ceremony and trading across the region [37,38]. However, the antiquity of these activities is not clear from the current state of the research. In a review of the subject, the Australian ethnographic literature is described as scant though detailed accounts of propagule movement, planting or cultivation, often with ceremonial elements [13]. The archaeological record suggests humans began to permanently occupy tropical rainforests in very low numbers at least $8 \mathrm{kya}$, with intensive settlement around 2 kya [39]. However, the archaeological record is also sparse, and it is possible that human rainforest occupation is much older. Additionally, the occurrence of pre-domesticates of New Guinea crops such as taro (Colocasia esculenta), yam (Dioscorea alata) and bananas (Musa acuminata) suggests that there was an "experimental horticultural province" [40] in northern Australia (including the northern section of the study region). These rainforest food plants spread to the Australian continent either while it was still contiguous with the New Guinea landmass in the terminal Pleistocene/early Holocene and/or via maritime human dispersal following sea-level rise in the mid-late Holocene [5,21].

Researchers that seek to retrace past Indigenous dispersal need to consider the dispersal capacity of faunal or other vectors in the study area. The relationship between fleshy fruit size and the dispersal potential of woody species has been successfully demonstrated among plants of the east Australian rainforests. Here, plants with small fleshy fruit are widely dispersed by birds and are typically characterised by low population structure and have potential for colonisation of new areas via long-distance dispersal (LDD) [41,42]. This genomic background would make it difficult to identify populations translocated by humans. In contrast, following the extinction of megafauna from the Australian continent between 50 to 16 kya [43], large-seeded plants lost an important mechanism for LDD and the ability to re-colonise areas of suitable habitat following the end of the Last Glacial Maximum (25-16 kya). Consequently, large-seeded rainforest species generally have greater between-population genomic divergence and occupy smaller geographic ranges than their small-fruited counterparts $[42,44]$. We anticipate that the strong population structure in large-fruited species would contrast with the genomic signal left by Indigenous dispersal events that post-date the megafauna extinction.

Here, we present a screening strategy that employs simple genomic tests to identify signals of dispersal within long-lived non-crop plant species that may be attributed to Indigenous peoples. We sought to investigate whether fleshy fruited species with a known 
history of Indigenous use carry genomic patterns that are distinctive from expected signatures of widespread faunal dispersal. We were also interested in whether these signatures could be identified in other species that are likely to have been a nutritious food source, but for which we lack historic evidence of their extensive use by Indigenous groups.

We employed an opportunistic sample design to develop nuclear DNA (nDNA) genotyping-by-sequencing and whole-chloroplast (cpDNA) SNP datasets of east Australian rainforest trees that fall into one of five fruit-trait categories that impact dispersal capacity. We tested for four genomic signals of dispersal with different patterns expected for species with a history of long-term isolation, long-term faunal-mediated dispersal, or dispersal following long-term isolation (Table 1, Materials and Methods 2.6). Signal 1 "low Fst values and the absence of isolation-by-distance (IBD)" is the outcome of recent and/or rapid dispersal, Signal 2 "admixture between sites" is produced by dispersal following long-term isolation, such as across a biogeographic barrier, Signal 3 "genomic outliers within sites" is produced by very recent long-distance dispersal (LDD) between formerly isolated sites. Signal 4 "long-distance dispersal of haplotypes" is produced by recent dispersal following long-term isolation and is distinct from range-wide haplotype sharing that is consistent with long-term faunal dispersal.

Table 1. The patterns expected from four tests of dispersal assuming different dispersal traits and histories. For each signal, we expected different results for species with a history of long-term isolation, long-term faunal-mediated dispersal or dispersal following long-term isolation. Note that more than one dispersal scenario is hypothesised for species in the small fruit categories. Signal $1=$ "low Fst values and absence of isolation-by-distance". Signal 2 = "admixture between sites". Signal $3=$ "genomic outliers within sites". Signal $4=$ "haplotype long-distance dispersal". $\checkmark=$ expected genomic signal from post-megafauna Indigenous dispersal. $\boldsymbol{X}=$ genomic pattern not consistent with post-megafauna Indigenous dispersal. IBD = isolation-by-distance. LDD $=$ long-distance dispersal.

\begin{tabular}{|c|c|c|c|c|}
\hline Dispersal Trait & Signal 1 & Signal 2 & Signal 3 & Signal 4 \\
\hline $\begin{array}{c}\text { Small fruit } \\
\text { faunal dispersed }\end{array}$ & $\begin{array}{l}x \text { Low Fst values \& IBD } \\
\text { (long-term dispersal) }\end{array}$ & $\begin{array}{l}\checkmark \text { Admixture between } \\
\text { sites (dispersal following } \\
\text { long-term isolation) } \\
x \text { Homogeneity among } \\
\text { sites (long-term } \\
\text { dispersal) }\end{array}$ & $\begin{array}{c}\checkmark \text { Within-site outliers } \\
\text { (recent LDD) } \\
x \text { No outliers } \\
\text { (long-term dispersal) }\end{array}$ & $\begin{array}{c}x \text { Range-wide haplotype } \\
\text { sharing (long-term } \\
\text { dispersal) } \\
\checkmark \text { Single widespread } \\
\text { haplotype (recent rapid } \\
\text { dispersal) }\end{array}$ \\
\hline $\begin{array}{l}\text { Small fruit } \\
\text { Indigenous } \\
\text { dispersed }\end{array}$ & $\begin{array}{l}\checkmark \text { Low Fst values \& } \\
\text { absence of IBD (recent } \\
\text { rapid dispersal) }\end{array}$ & $\begin{array}{l}\checkmark \text { Admixture between } \\
\text { sites (dispersal following } \\
\text { long-term isolation) } \\
x \text { Homogeneity among } \\
\text { sites (long-term } \\
\text { dispersal) }\end{array}$ & $\begin{array}{l}\checkmark \text { Within-site outliers } \\
\text { (dispersal following } \\
\text { long-term isolation) }\end{array}$ & $\begin{array}{c}x \text { Range-wide haplotype } \\
\text { sharing (long-term } \\
\text { dispersal) } \\
\checkmark \text { Single widespread } \\
\text { haplotype (recent rapid } \\
\text { dispersal) }\end{array}$ \\
\hline $\begin{array}{c}\text { Large fruit } \\
\text { faunal dispersed }\end{array}$ & $\begin{array}{l}x \text { High Fst values with } \\
\text { or without IBD } \\
\text { (long-term isolation) }\end{array}$ & $\begin{array}{l}x \text { Structure across } \\
\text { barriers (long-term } \\
\text { isolation) }\end{array}$ & $\begin{array}{c}x \text { Differentiation } \\
\text { amongst sites and no } \\
\text { outliers (long-term } \\
\text { isolation) }\end{array}$ & $\begin{array}{l}\text { x Haplotype divergence } \\
\text { (long-term isolation) }\end{array}$ \\
\hline $\begin{array}{l}\text { Large fruit } \\
\text { Indigenous } \\
\text { dispersed }\end{array}$ & $\begin{array}{l}\checkmark \text { Low Fst values \& } \\
\text { absence of IBD (recent } \\
\text { rapid dispersal) }\end{array}$ & $\begin{array}{l}\checkmark \text { Admixture between } \\
\text { sites (dispersal following } \\
\text { long-term isolation) }\end{array}$ & $\begin{array}{l}\checkmark \text { Within-site outliers } \\
\text { (dispersal following } \\
\text { long-term isolation) }\end{array}$ & $\begin{array}{c}\checkmark \text { Haplotype sharing } \\
\text { between differentiated sites } \\
\text { (dispersal following } \\
\text { long-term isolation) } \\
\checkmark \text { Single widespread } \\
\text { haplotype (recent rapid } \\
\text { dispersal) }\end{array}$ \\
\hline
\end{tabular}

Species with signatures of dispersal following long-term isolation were regarded as candidates for further investigation of putative Indigenous dispersal histories. For these candidates, we outline a strategy to test specific dispersal hypotheses using more comprehensive sampling and coalescent analyses. 


\section{Materials and Methods}

\subsection{Study System}

The study area extended along the coastal plains and ranges of eastern Australia from the tropical monsoonal rainforests of Iron Range $\left(12^{\circ} 42^{\prime} \mathrm{S}\right)$ in the Cape York Peninsula, Queensland (QLD) to the scattered subtropical forests around Glennifer, New South Wales (NSW; $30^{\circ} 22^{\prime} \mathrm{S}$; Figure 1 ). The study species are primarily located in the Australian Wet Tropics (AWT; $15^{\circ} 40^{\prime}$ to $19^{\circ} 15^{\prime} \mathrm{S}$ ) or northern NSW (NNSW) and some extend through the intervening regions of Central QLD (CQLD; $20^{\circ}$ to $24^{\circ} \mathrm{S}$ ) and Southeast QLD (SEQ; $\sim 25^{\circ}$ to $28^{\circ} \mathrm{S}$ ). There are several breaks in wet forest habitat within and between these regions [45].

During the Quaternary, climate-driven cycles of wet forest habitat contraction and reexpansion led to periods of genetic isolation and admixture for many rainforest species [41,46,47]. The AWT bioregion comprises a mosaic of tropical upland and lowland forests separated by drier corridors of mixed wet/dry habitats that act as "permeable" genetic or distributional barriers for some rainforest species [48-52]. This includes the Black Mountain Corridor (BMC) [49] and Cairns-Cardwell Lowlands (CCL) $[44,48,50]$. The subtropical rainforests in NNSW are highly fragmented, with upland sites isolated by extensive low-lying river systems. The Clarence River Corridor (CRC) is also a dry habitat break for some mesic species and has played a role in diversification between SEQ and upland regions of the mid-north coast of NSW [46,47,53].

Specialised large-fruit dispersers have been historically absent from NNSW and SEQ, and local dispersal rates are expected to be lower in the region [54,55]. Therefore, it is assumed that large fleshy fruit in southern forests have no means of long-distance dispersal except through human activity. This pattern appears to be less pronounced in the AWT [56], where fruit up to $62 \mathrm{~mm}$ can be locally dispersed $(\leq 2 \mathrm{~km})$ by non-volant vertebrates such as the southern Cassowary (Casuarius casuarius johnsonii) [57,58]. Meanwhile fruit bats (Pteropus spp.) and birds would facilitate dispersal of small-fruited species over longer distances across the whole study area. 


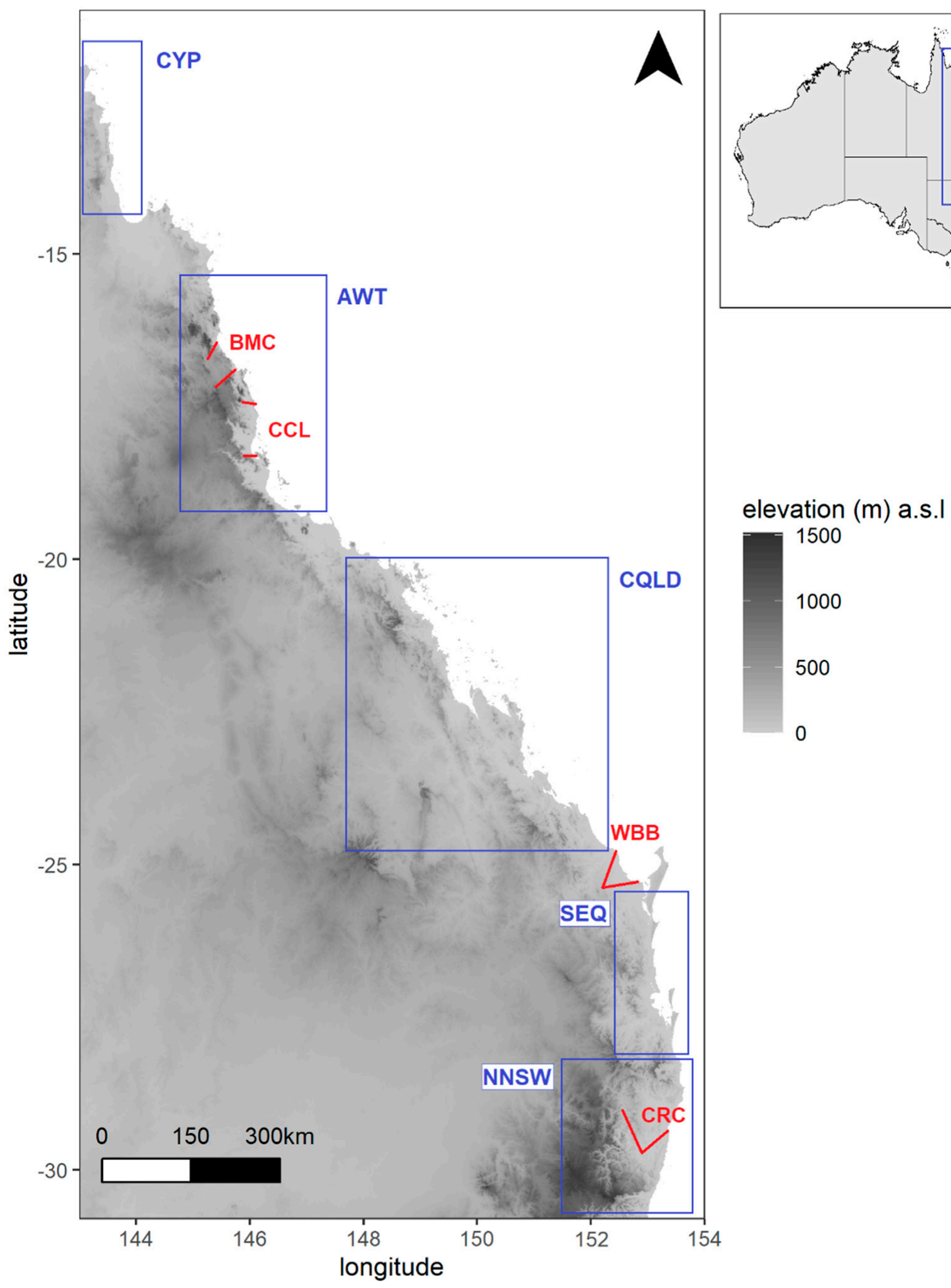

Figure 1. The study area in eastern Australia. Geographic regions separated by disjunctions of rainforest vegetation are indicated by the blue boxes. NNSW = Northern New South Wales, SEQ = Southeast Queensland, CQLD = Central Queensland, AWT = Australian Wet Tropics, CYP = Cape York Peninsula. Low elevation biogeographic barriers that structure the genomic variation in some of the study species are demarcated by red lines. $\mathrm{CRC}=$ Clarence River Corridor, WBB = Wide Bay-Burnett, $\mathrm{CCL}=$ Cairns-Cardwell Lowlands, $\mathrm{BMC}=$ Black Mountain Corridor. 


\subsection{Study Design}

For our core analyses, we selected three groups of co-generic or closely related rainforest species with fleshy fruit and/or edible nutritious seed (Table 1 ). This includes $4 \times$ Elaeocarpus (Elaeocarpaceae), $1 \times$ Pleioluma, $1 \times$ Planchonella and $2 \times$ Niemeyera (Sapotaceae); $3 \times$ Endiandra and $1 \times$ Bielschmiedia (Lauraceae). The fruit of these species typically contain a single large seed that comprises most of the fruit. Additionally, we included Castanospermum australe (Fabaceae), in which the genomic impacts of dispersal by Bundjalung people in NNSW has been previously demonstrated [32]. For broader context, 12 additional species from other families were included in our initial analyses, 3 of which have inedible winddispersed fruit. We employed an opportunistic rather than comprehensive sample strategy that captured the core distribution of each of the study species, including their presence across putative biogeographic barriers (see Table S1 for details of sample collection).

We grouped species according to the following fruit traits: large fleshy and Indigenous used, small fleshy and Indigenous used, large fleshy, small fleshy, wind dispersed. Following [38], our fruit-size categories were based on maximum width and defined as large $(\geq 30 \mathrm{~mm})$ or small $(\leq 30 \mathrm{~mm}$; see Table 2$)$. These categories correspond with the maximum size of fruit that can be ingested whole by the largest volant dispersers in the southern subtropical rainforests [57]. Fruit size was obtained from Australian Tropical Rainforest Plants Edition 8 (https://apps.lucidcentral.org/rainforest/text/intro/index.html accessed on 6 November 2021) or from plantNET (https:/ / plantnet.rbgsyd.nsw.gov.au/ accessed on 6 November 2021). Species were categorised as Indigenous used if we found archaeological or ethnographic reports that indicate past or ongoing consumption by Indigenous groups in Australia (Table 2). The other species may also have been Indigenous used, but we could not find reports of this.

Among our study species, Planchonella australis is an anomaly since it has large fleshy fruit with 1-5 smaller seeds that can potentially be dispersed by fruit bats. Note that although fruit size is a variable trait, the lower end of the range is generally recorded from fruit with inviable seed or no seed at all and would not contribute to the gene pool of the species. Therefore, although a maximum fruit width of $<30 \mathrm{~mm}$ has been recorded for P. australis, Niemeyera whitei and Elaeocarpus johnsonii, we included these in the large fruit categories as they are primarily much wider than $30 \mathrm{~mm}$. 
Table 2. The study species and their fruit traits, the genomic data used in the study and references that report use of each species by Indigenous Australians. Fruit traits: $\mathrm{S}=$ Small $(<30 \mathrm{~mm}), \mathrm{L}=$ Large $(>30 \mathrm{~mm}), \mathrm{F}=$ Fleshy, $\mathrm{W}=$ Woody, $\mathrm{O}=$ Other. Seed traits: $\mathrm{L}=$ Large, $\mathrm{S}=$ Small. nDNA = nuclear DNA. cpDNA = chloroplast DNA. Fst $=$ Wright's Fixation Index. Location: AWT $=$ Australian Wet Tropics, CQLD = Central Queensland, SEQ = Southeast Queensland, NNSW = Northern New South Wales, SBMC = South of the Black Mountain Corridor in the AWT, NBMC $=$ North of the Black Mountain Corridor in the AWT

\begin{tabular}{|c|c|c|c|c|c|c|c|c|c|}
\hline Family & Species & Common Names & Fruit Trait & $\begin{array}{l}\text { Max. Fruit } \\
\text { Width (mm) }\end{array}$ & $\begin{array}{c}\text { Seed } \\
\text { Number \& } \\
\text { Traits }\end{array}$ & $\begin{array}{l}\text { nDNA } \\
\text { Markers } \\
\text { (SNPs) }\end{array}$ & $\begin{array}{l}\text { cpDNA } \\
\text { Sequence } \\
\quad(b p)\end{array}$ & $\begin{array}{c}\text { Mantel score } \\
(p=0.05) \\
* \text { Three Sites } \\
\text { Only }\end{array}$ & Reported Indigenous Use \\
\hline \multicolumn{10}{|c|}{ Study Species } \\
\hline Fabaceae & C. australe & $\begin{array}{l}\text { Moreton Bay } \\
\text { chestnut, black } \\
\text { bean, bean tree }\end{array}$ & $\mathrm{LO}$ & 45 & $3-5 \mathrm{~L}$ & $\begin{array}{c}38,124 \\
18,443 \text { (north) } \\
20,705 \text { (south) }\end{array}$ & & $\begin{array}{c}0.67(p=0.04) \\
\text { AWT } \\
0.43(p=0.18) \\
\text { NNSW }\end{array}$ & $\begin{array}{l}\text { 'Black bean was a staple food of many } \\
\text { northern rainforest Aboriginal people } \\
\text { and is still prepared and eaten today.' } \\
\text { (cited [59]). } \\
\text { Ethnographic records of consumption } \\
\text { by Indigenous peoples (AWT) [60-64]. } \\
\text { Seed detoxification described in the } \\
\text { AWT [65,66] and in } \\
\text { NNSW/SEQ [32,67,68]. }\end{array}$ \\
\hline Lauraceae & $\begin{array}{l}\text { Bielschmiedia } \\
\text { bancroftii }\end{array}$ & $\begin{array}{l}\text { Yellow walnut, } \\
\text { yellow nut, Canary } \\
\text { ash }\end{array}$ & $\mathrm{LO}$ & $75 \times 62$ & $1 \mathrm{~L}$ & 2080 & 108,132 & $\begin{array}{c}0.36(p=0.33) \\
\text { AWT }\end{array}$ & $\begin{array}{l}\text { Seed preparation described in the } \\
\text { AWT [61]. } \\
\text { Archaeological evidence of seed } \\
\text { processing in the AWT }[39,69] .\end{array}$ \\
\hline Sapotaceae & P. australis & $\begin{array}{l}\text { Black apple, brush } \\
\text { apple, wild plum, } \\
\text { native plum }\end{array}$ & LF & 50 & $1-5 \mathrm{~S}$ & 24,873 & 86,899 & $\begin{array}{l}0.63(p=0.17) \\
\text { NNSW }^{*}\end{array}$ & $\begin{array}{l}\text { Ethnographic records [67]. } \\
\text { Bush tucker guide [70]. }\end{array}$ \\
\hline Elaeocarpaceae & $\begin{array}{l}\text { Elaeocarpus } \\
\text { bancroftii }\end{array}$ & $\begin{array}{l}\text { Kuranda quandong, } \\
\text { ebony heart, } \\
\text { nutwood, Johnstone } \\
\text { River almond }\end{array}$ & LF & $55 \times 40$ & $1 \mathrm{~L}$ & 17,085 & & $\begin{array}{c}0.14(p=0.32) \\
\text { AWT }\end{array}$ & $\begin{array}{c}\text { Ethnographic records }[67,71] \text {. } \\
\text { Bush tucker guide }[68,70] . \\
\text { Archaeological records of seed } \\
\text { preparation }[72] .\end{array}$ \\
\hline
\end{tabular}


Table 2. Cont.

\begin{tabular}{|c|c|c|c|c|c|c|c|c|c|}
\hline Family & Species & Common Names & Fruit Trait & $\begin{array}{l}\text { Max. Fruit } \\
\text { Width (mm) }\end{array}$ & $\begin{array}{c}\text { Seed } \\
\text { Number \& } \\
\text { Traits }\end{array}$ & $\begin{array}{l}\text { nDNA } \\
\text { Markers } \\
\text { (SNPs) }\end{array}$ & $\begin{array}{l}\text { cpDNA } \\
\text { Sequence } \\
\quad(b p)\end{array}$ & $\begin{array}{l}\text { Mantel score } \\
(p=0.05) \\
\text { * Three Sites } \\
\text { Only }\end{array}$ & Reported Indigenous Use \\
\hline Lauraceae & $\begin{array}{l}\text { Endiandra } \\
\text { compressa }\end{array}$ & & $\mathrm{LF}$ & $71 \times 60$ & $1 \mathrm{~L}$ & 4025 & 107,869 & $\begin{array}{c}0.91(p=0.33) \\
\text { AWT }\end{array}$ & \\
\hline Lauraceae & $\begin{array}{l}\text { Endiandra } \\
\text { globosa }\end{array}$ & Black walnut & LF & $60 \times 60$ & $1 \mathrm{~L}$ & 24,382 & 107,910 & $\begin{array}{c}0.99(p=0.33) \\
\text { AWT }\end{array}$ & \\
\hline Lauraceae & $\begin{array}{l}\text { Endiandra } \\
\text { pubens }\end{array}$ & Hairy walnut & $\mathrm{LF}$ & $75 \times 75$ & $1 \mathrm{~L}$ & 23,322 & 107,371 & $\begin{array}{l}0.99(p=0.17) \\
\text { NNSW }^{*}\end{array}$ & \\
\hline Sapotaceae & $\begin{array}{l}\text { Niemeyera } \\
\text { prunifera }\end{array}$ & & LF & $50 \times 50$ & $1 \mathrm{~L}$ & 22,778 & 84,279 & $\begin{array}{c}0.91(p=0.12) \\
\text { AWT }\end{array}$ & \\
\hline Sapotaceae & N. whitei & & $\mathrm{LF}$ & $20-50$ & $1 \mathrm{~L}$ & 10,669 & 87,841 & $\begin{array}{l}0.61(p=0.33) \\
\text { NNSW * }\end{array}$ & \\
\hline Elaeocarpaceae & E. johnsonii & Kuranda quandong & $\mathrm{LO}$ & $40 \times 25$ & $1 \mathrm{~L}$ & 1274 & & $\begin{array}{c}0.99(p=0.33) \\
\text { AWT }^{*}\end{array}$ & $\begin{array}{l}\text { Bush tucker guide described the seed } \\
\text { as edible [73]. }\end{array}$ \\
\hline Elaeocarpaceae & $\begin{array}{l}\text { Elaeocarpus } \\
\text { grandis }\end{array}$ & $\begin{array}{l}\text { Blue quandong, } \\
\text { silver quandong, } \\
\text { blue fig }\end{array}$ & SF & $33 \times 33$ & $1 \mathrm{~L}$ & 10,273 & & $\begin{array}{l}0.54(p=0.13) \\
\text { NBMC } \\
0.13(p=0.35) \\
\text { SBMC } \\
0.99(p=0.33) \\
\text { CQLD* }\end{array}$ & $\begin{array}{l}\text { 'You can eat the thin layer of flesh of } \\
\text { the ripe purple-blue fruits when flesh } \\
\text { is soft.' (cited [59]). } \\
\text { Bush tucker guide describes edible } \\
\text { fruit [70]. }\end{array}$ \\
\hline Elaeocarpaceae & $\begin{array}{l}\text { Elaeocarpus } \\
\text { reticulatus }\end{array}$ & & $\mathrm{SF}$ & $12 \times 12$ & $1 \mathrm{~S}$ & 14,731 & & $\begin{array}{c}0.56(p<0.01) \\
\text { NNSW }\end{array}$ & $\begin{array}{l}\text { B. McLeod describes the fruit as "good } \\
\text { bush tucker tea" that can be eaten raw } \\
\text { or as a jam [74] (NB: reference is from } \\
\text { outside of study area). }\end{array}$ \\
\hline Sapotaceae & $\begin{array}{l}\text { Pleioluma } \\
\text { queens- } \\
\text { landica }\end{array}$ & & SF & $22 \times 9$ & $1 \mathrm{~S}$ & 15,270 & 85,895 & & \\
\hline Lauraceae & $\begin{array}{l}\text { Endiandra } \\
\text { discolor }\end{array}$ & & SF & $17 \times 13$ & $1 \mathrm{~S}$ & 23,081 & 107,031 & $\begin{array}{c}-0.05(p=0.42) \\
\text { NNSW }\end{array}$ & \\
\hline
\end{tabular}


Table 2. Cont.

\begin{tabular}{|c|c|c|c|c|c|c|c|c|c|}
\hline Family & Species & Common Names & Fruit Trait & $\begin{array}{l}\text { Max. Fruit } \\
\text { Width (mm) }\end{array}$ & $\begin{array}{l}\text { Seed } \\
\text { Number \& } \\
\text { Traits }\end{array}$ & $\begin{array}{l}\text { nDNA } \\
\text { Markers } \\
\text { (SNPs) }\end{array}$ & $\begin{array}{l}\text { cpDNA } \\
\text { Sequence } \\
\quad(b p)\end{array}$ & $\begin{array}{l}\text { Mantel score } \\
(p=0.05) \\
* \text { Three Sites } \\
\text { Only }\end{array}$ & Reported Indigenous Use \\
\hline \multicolumn{10}{|c|}{ Fst Only } \\
\hline Lauraceae & $\begin{array}{l}\text { Endiandra } \\
\text { introrsa }\end{array}$ & & $\mathrm{LF}$ & $50 \times 50$ & & 3461 & & & \\
\hline Lauraceae & $\begin{array}{l}\text { Bielschmiedia } \\
\text { tooram }\end{array}$ & $\begin{array}{l}\text { Brown walnut, } \\
\text { Tooram walnut }\end{array}$ & $\mathrm{LF}$ & $55 \times 35$ & & 3461 & & & $\begin{array}{l}\text { Bush tucker guide describes edible } \\
\text { fruit [70]. } \\
\text { Bush tucker guide describes edible } \\
\text { seed [73]. }\end{array}$ \\
\hline Lauraceae & $\begin{array}{l}\text { Bielschmiedia } \\
\text { volckii }\end{array}$ & & $\mathrm{LF}$ & $67 \times 65$ & & 3461 & & & \\
\hline Sapindaceae & $\begin{array}{l}\text { Diploglottis } \\
\text { australis }\end{array}$ & $\begin{array}{l}\text { Native tamarind, } \\
\text { tamarind tree, } \\
\text { orange tamarind }\end{array}$ & SF & 15 & & 4640 & & $\begin{array}{c}0.88(p<0.01) \\
\text { NNSW }\end{array}$ & $\begin{array}{l}\text { Ethnographic sources }[60,67] \text { and bush } \\
\text { tucker guide }[70] \text { describe the culinary } \\
\text { properties of the fruit. }\end{array}$ \\
\hline Lauraceae & $\begin{array}{l}\text { Neolitsea } \\
\text { dealbata }\end{array}$ & & SF & $11 \times 11$ & & 2881 & & $\begin{array}{c}0.91(p<0.01) \\
\text { NNSW }\end{array}$ & \\
\hline Lauraceae & $\begin{array}{l}\text { Cryptocaria } \\
\text { glaucesens }\end{array}$ & & SF & $15 \times 18$ & & 14,970 & & $\begin{array}{c}0.89(p<0.01) \\
\text { NNSW }\end{array}$ & \\
\hline Elaeocarpaceae & $\begin{array}{l}\text { Sloanea } \\
\text { australis }\end{array}$ & & SF & $17 \times 17$ & & 7429 & & $\begin{array}{c}0.59(p<0.01) \\
\text { NNSW }\end{array}$ & \\
\hline Myrtaceae & $\begin{array}{l}\text { Tristaniopsis } \\
\text { laurina }\end{array}$ & $\begin{array}{l}\text { Water gum, } \\
\text { kanooka }\end{array}$ & $\mathrm{W}$ & $10 \times 6$ & & 13,841 & & $\begin{array}{c}0.59(p<0.01) \\
\text { NNSW }\end{array}$ & \\
\hline Myrtaceae & $\begin{array}{l}\text { Tristaniopsis } \\
\text { collina }\end{array}$ & $\begin{array}{l}\text { Mountain water } \\
\text { gum }\end{array}$ & W & $10 \times 6$ & & 10,721 & & $\begin{array}{c}0.82(p<0.01) \\
\text { NNSW }\end{array}$ & \\
\hline Cunoniaceae & $\begin{array}{l}\text { Ceratopetalum } \\
\text { apetalum }\end{array}$ & Coachwood & W & $>8$ & & 659 & & $\begin{array}{c}0.75(p<0.01) \\
\text { NNSW }\end{array}$ & \\
\hline
\end{tabular}




\subsection{Simulation of Hypothetical Dispersal Scenarios}

The premise of our screening strategy is that species with a history of post-megafauna isolation followed by recent Indigenous dispersal would produce genomic patterns that are distinct from widespread and long-term faunal dispersal. We sought to verify this assumption by simulating genetic differentiation of a species under 9 hypothetical dispersal scenarios. We calculated the pairwise Fst values from each of the simulated scenarios to determine whether patterns of population differentiation are identifiably distinct between long-term faunal and recent Indigenous dispersal (see Appendix A for full description of methods and results).

\subsection{Nuclear and Chloroplast Genomic Methods}

For all samples, nDNA extraction from leaf samples and SNP genotyping using DArTseq technology [75] was undertaken at Diversity Arrays Technology Pty Ltd. (Canberra, Australia). The DArTseq data were obtained from a prior study of T. laurina and T. collina [47] and D. australis, C. serratifolia, Elaeocarpus reticulatus, N. dealbata and S. australis (see Table S1). The data for all other species are novel to this study. We followed [46] and filtered markers according to reproducibility average (proportion of technical replicates for which the marker score is consistent) and call rate (proportion of individuals with non-missing scores). We selected markers with a reproducibility average of at least 0.96 and a minimum call rate of 0.80 .

In addition, we obtained novel comparative cpDNA sequence data for Sapotaceae and Lauraceae to determine the ancestral relationships between populations and samples. Whole-chloroplast sequencing was undertaken at Deakin Genomics Research and Discovery Facility (Geelong, Australia) and we assembled the genomes de novo with ORG.Asm [76]. We used CLC Genomics Workbench 20.0 (QIAGEN, Denmark) to inspect read quality and depth, and map reads against annotated reference sequences obtained from GeSeq [77]. We used the default settings to map Lauraceae samples against E. globosa (Accession: KT588614) and Sapotaceae samples against Pouteria campechiana (Accession: NC033501). For read conflicts, we used the quality score and vote options to determine the consensus sequence and we filtered variants with a coverage $<8$ or read consensus $<60 \%$. After removing areas of low coverage, the Lauraceae chloroplast sequence alignments ranged between 106,112 and 108,132 bp long (Table 2). The read coverage and quality were generally poorer for Sapotaceae species, and the cleaned alignments were between 84,279 and 87,841 bp.

We aligned the species libraries with the relevant reference sequence using the MEGA alignment function in Geneious Prime 2021.1.1 (Biomatters, New Zealand). To eliminate potential sequence errors, we removed non-synonymous variants in coding regions. To investigate the possibility of contamination in libraries with unexpectedly high variation, we extracted sequences that mapped to the $y c f 1$ and $n d h H$ genes and used the BLAST function in GenBank with default settings to determine if any samples matched with libraries of algae or other distantly related species.

\subsection{Assessment of Fruit Traits and Genetic Connectivity}

We calculated pairwise genetic distances for all 25 species to verify our primary assumption that species with large fruit have lower dispersal rates than wind-dispersed or small-fruit species. Pairwise Fst values were calculated using the R package BEDASSLE [78] under the Weir and Hill model [79]. Then, for each species, we took the average of their pairwise Fst values at $50 \mathrm{~km}$ distance intervals, starting from 0 to $50 \mathrm{~km}$ up to 651 to $700 \mathrm{~km}$. To visualise how fruit traits influence gene flow over each distance interval, we constructed violin plots of results organised by fruit trait. As there were only a few observations above $300 \mathrm{~km}$, we plotted distance classes between 301-700 km together for visual clarity. Small-fruited species were expected to show lower pairwise Fst values than large fruit species. 


\subsection{Genomic Tests of Dispersal Signals}

We sought to identify whether the core 15 study species show any of the four signals of putative Indigenous dispersal described in Table 1. For each signal, we expected different results for species with a history of long-term isolation, long-term faunal-mediated dispersal, or dispersal following long-term isolation. To identify candidates that warrant an investigation of Indigenous dispersal histories, we sought to eliminate species that show signals overwhelmingly consistent with long-term faunal-mediated dispersal or long-term isolation. Signals more consistent with dispersal following long-term isolation were hypothesised to be the outcome of Indigenous-mediated dispersal following isolation driven by the megafauna extinction.

To test for Signal 1 "combination of low Fst values and absence of IBD", we performed a Pearson Mantel test on each species' genetic and geographic distance matrices with 999 permutations $(p=0.05)$. The distance matrices were linearised Fst values (Fst/ $(1-$ Fst)) against log geographic distance $(\mathrm{km})$ and all calculations were made in the R package vegan 2.5-7 [80]. Where relevant, we subdivided the datasets to construct distance matrices within the AWT and NNSW. Given the sparse sample design and our aims to develop a screening strategy, we were more interested in identifying overall patterns of IBD than statistical significance.

Signal 1 is produced by recent and rapid radiation. This pattern may be attributed to extensive Indigenous dispersal, although other mechanisms of recent widespread migration cannot be excluded for small-fruited species. In the absence of Indigenous dispersal, largefruited species were expected to show high Fst values consistent with long-term isolation. The impact of IBD was expected only in the absence of barriers. On the other hand, rangewide faunal dispersal in a stable system is likely to yield low Fst values in combination with IBD.

For Signals 2-3, we used the STRUCTURE-like genotype assignment algorithm implemented by R package sNMF [81] to assess the degree of shared ancestry between samples. We modeled $K=2-10$ ancestral genotypes for each species, with 10 replicates per model. The cross-entropy criterion was used to evaluate model suitability in SNMF and we plotted the mean individual genotype assignments for $K=2-4$ models. Given our sparse sample scheme may confound the genotype assignment algorithm, we verified the sNMF results with a principal components analysis (PCA) on the genomic variation among samples. Ordination was visualised in the first 3 primary axes of variation, with samples coloured according to latitude to determine whether genetic structure is geographic.

In our assessment of Signal 2 "admixture between sites", we looked for sites where most samples had admixed sNMF profiles (e.g., $\leq 75 \%$ of the dominant genotype) in the optimal $\mathrm{K}$ model. Admixed profiles are a putative signal of secondary contact and admixture after many generations of isolation and could be facilitated by Indigenous dispersal or by faunal dispersal amongst small-fruited species. However, admixed profiles could alternatively be the outcome of incomplete lineage sorting due to vicariance, a recent bottleneck or admixture with an unsampled or extinct lineage [82]. We expected large-fruited species to show stronger population structure than small-fruited species, and Indigenous-used species to show some admixture of genotypes separated by barriers or disjunct regions. Regardless of human influence, small-fruited species were expected to show either a single genotype indicative of long-term range-wide connectivity or admixture consistent with post-glacial re-connectivity.

Signal 3 "within-site outliers" refers to samples that show a genotype that is distinct from most of the sample site (in the PCA and sNMF plot). Such a pattern may be produced by recent LDD and is hypothesised to be the outcome of recent Indigenous dispersal (reinforcement). Signals of LDD within small-fruited species may also be attributed to volant faunal dispersers, although this pattern is not expected.

To test Signal 4 "haplotype LDD", the cleaned cpDNA alignments were exported for a Neighbour-Joining network analysis $($ epsilon $=0$ ) of haplotypes in PopART (New Zealand) [83]. We looked for haplotype sharing or closely related haplotypes between 
otherwise highly genetically differentiated sites and/or disjunct sites as a putative signal of LDD. For large-fruited species, such a pattern is hypothesised to be the outcome of Indigenous-mediated reinforcement between previously isolated sites. Meanwhile assisted migrations or introductions may result in patterns consistent with rapid expansion, such as low haplotype variation between disjunct sites or a single widespread haplotype. Smallfruited species were expected to show extensive haplotype sharing and few mutations between haplotypes, indicative of long-term population connectivity. A single widespread haplotype may be indicative of rapid expansion facilitated by either Indigenous or faunal dispersal. Meanwhile large-fruited species without human influence were expected to retain strong haplotype differentiation between sites or across barriers.

\section{Results}

\subsection{Fruit Traits and Genetic Connectivity}

The violin plots of species-mean pairwise Fst shows that as a group, species with large fleshy fruit have higher median pairwise Fst values than the wind-dispersed or small fleshyfruited species across all distance intervals excluding 201-250 km (Figure 2). This supports our founding premise that faunal vectors facilitate extensive gene flow within small fruit species, while large fruit species lack a mechanism of long-distance seed dispersal and thus have lower rates of gene flow. The large fruit though small-seeded P. australis has lower Fst values than the other categories and may be attributed to Indigenous-assisted dispersal or animal dispersal (Table S2). Compared with fleshy fruit species, the range of Fst values is small in the wind-dispersed category and increases only marginally with geographic distance. This indicates that wind dispersal is relatively uniform in the study area, while gene flow within fleshy fruit species is sensitive to the type and/or availability of vertebrate dispersers.

\section{Pairwise Fst across $50 \mathrm{~km}$ distance intervals}

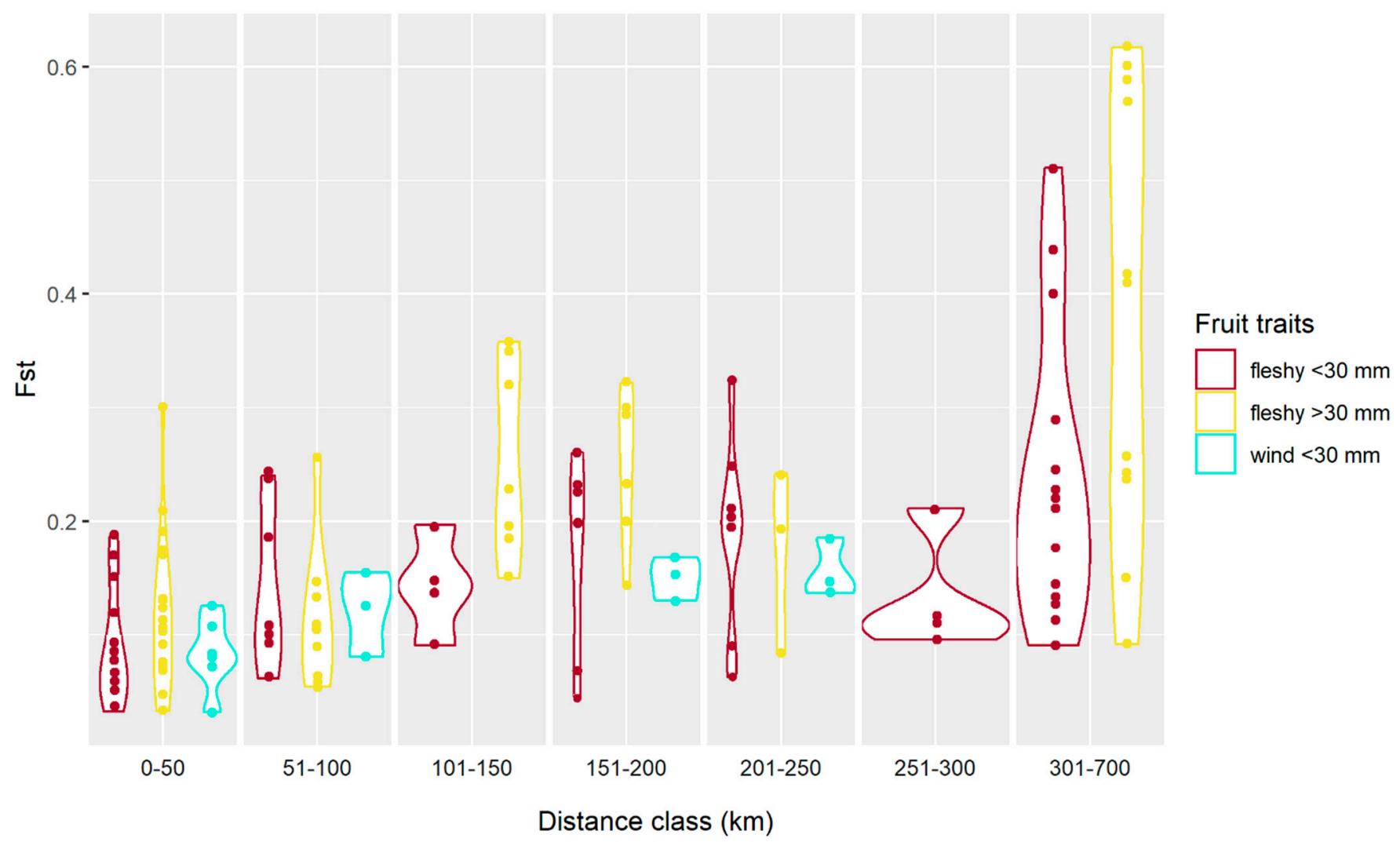

Figure 2. Violin plots of the average pairwise Fst values calculated for 25 species at $50 \mathrm{~km}$ distance intervals and coloured by fruit trait. 


\subsection{Simulation Study}

Overall, the nine simulated dispersal scenarios support the premise that long-term faunal dispersal and post-isolation Indigenous dispersal produce distinct patterns of genetic differentiation. The two hypothetical scenarios of post-glacial volant faunal dispersal show low Fst values though a prominent barrier effect (Figures A1 and A2). As expected, the post-megafauna isolation model yielded the greatest population structure amongst all dispersal scenarios (Figure A3).

The Indigenous dispersal scenarios produced varying patterns of differentiation depending on the pattern of migration and the length of the migration period. For instance, the symmetric island model of migration in hd1 and hd2 (Figures A4 and A5) yielded a greater homogenising effect than the distance-weighted migration of the faunal models. Models hd3 and hd6 with Indigenous dispersal 5000-4000 years ago exhibited higher Fst values due to the shorter and more ancient period of migration (Figures A6 and A9). In contrast with all other models, the lack of migration combined with the range expansion in hd4 yielded high Fst estimates excluding between the two recently diverged deme 0 and deme1 (Figure A7). The directional migration in hd5 and hd6 yielded higher Fst values and different population structure to the faunal dispersal scenarios (Figures A8 and A9).

\subsection{Genomic Tests of Dispersal Signals}

We identified five candidates for the investigation of Indigenous dispersal that displayed at least two positive signals of dispersal: C. australe, E. insignis, B. bancroftii, E. bancroftii and N. prunifera (Table 3).

Table 3. Summary of dispersal signals found in the study species. The presence or absence of these signals can be used to evaluate whether a species would make a suitable candidate to investigate the influence of Indigenous dispersal. Signal $1=$ "low Fst values and absence of IBD". Signal 2 = "admixture between sites". Signal 3 = "genomic outliers within sites". Signal 4 = "haplotype LDD". Species identified as candidates for Indigenous dispersal studies have an asterisk *

\begin{tabular}{|c|c|c|c|c|c|c|}
\hline Species & $\begin{array}{c}\text { Fruit } \\
>30 \mathrm{~mm}\end{array}$ & $\begin{array}{c}\text { Verified } \\
\text { Indigenous Use }\end{array}$ & $\begin{array}{l}\text { Signal } 1 \\
\text { nDNA }\end{array}$ & $\begin{array}{l}\text { Signal } 2 \\
\text { nDNA }\end{array}$ & $\begin{array}{l}\text { Signal } 3 \\
\text { nDNA }\end{array}$ & $\begin{array}{l}\text { Signal } 4 \\
\text { cpDNA }\end{array}$ \\
\hline C. australe (CYP/AWT) & $\checkmark$ & $\checkmark$ & $x$ & $\checkmark$ & $x$ & $x$ \\
\hline C. australe (SEQ/NNSW) * & $\checkmark$ & $\checkmark$ & $\checkmark$ & $\checkmark$ & $x$ & $x$ \\
\hline E. insignis * & $\checkmark$ & $\checkmark$ & $x$ & $x$ & $x$ & $\checkmark$ \\
\hline B. bancroftii * & $\checkmark$ & $\checkmark$ & $\checkmark$ & $x$ & $\checkmark$ & $\checkmark$ \\
\hline P. australis & $\checkmark$ & $\checkmark$ & $x$ & $x$ & $\checkmark$ & $x$ \\
\hline E. bancroftii * & $\checkmark$ & $\checkmark$ & $\checkmark$ & $\checkmark$ & $x$ & \\
\hline E. globosa (AWT) & $\checkmark$ & $x$ & $x$ & $x$ & $\checkmark$ & $x$ \\
\hline E. globosa (NNSW) & $\checkmark$ & $x$ & & & $\checkmark$ & $x$ \\
\hline E. compressa & $\checkmark$ & $x$ & $x$ & $x$ & $x$ & $x$ \\
\hline E.pubens & $\checkmark$ & $x$ & $x$ & $x$ & $x$ & $x$ \\
\hline N. prunifera * & $\checkmark$ & $x$ & $x$ & $x$ & $x$ & $\checkmark$ \\
\hline N. whitei & $\checkmark$ & $x$ & $x$ & $x$ & $x$ & $x$ \\
\hline E. johnsonii & $\checkmark$ & $x$ & $x$ & $x$ & $\checkmark$ & \\
\hline E. grandis & $x$ & $\checkmark$ & $\checkmark$ & $x$ & $\checkmark$ & \\
\hline E. discolor & $x$ & $x$ & $\checkmark$ & $\checkmark$ & $x$ & $\checkmark$ \\
\hline P. queenslandica & $x$ & $x$ & $x$ & $\checkmark$ & $x$ & $\checkmark$ \\
\hline E. reticulatus & $x$ & $x$ & $x$ & $x$ & $x$ & \\
\hline
\end{tabular}

\subsubsection{Large Fruit with Known History of Indigenous Use}

We assessed the northern and southern ranges of $C$. australe separately, due to the large geographic and genetic disjunction between the two regions. In the northern range, $C$. australe showed only one signal of dispersal (Table 3). We found low to moderate pairwise Fst values and a Mantel correlate consistent with IBD expected of non-anthropogenic dispersal (Table 2). The best supported sNMF models $(K=2-3)$ revealed divergence across 
the BMC and no outliers that may indicate LDD (Figure S1 and Figure 3a(ii)). The PCA ordination was most concordant with $K=3$, and both models suggest putative admixture or ILS across the BMC at sites ToS and CT (Signal 2; Figure 3a(iii)).
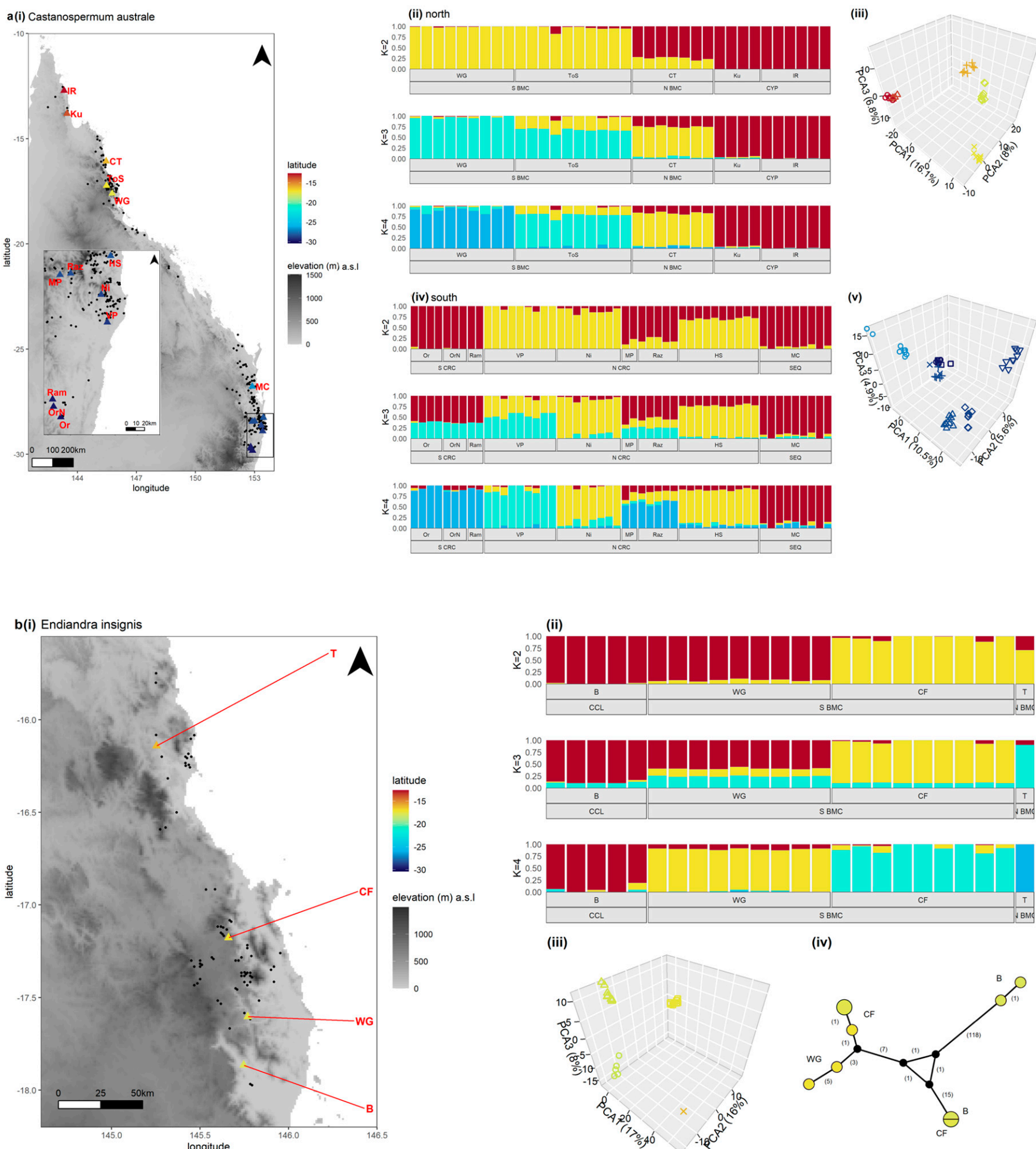

(iii)

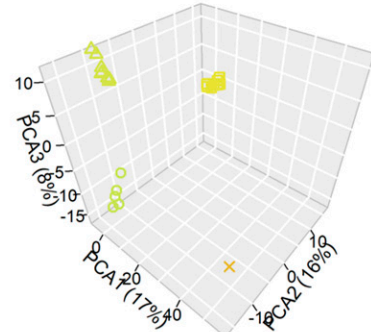

(iv)

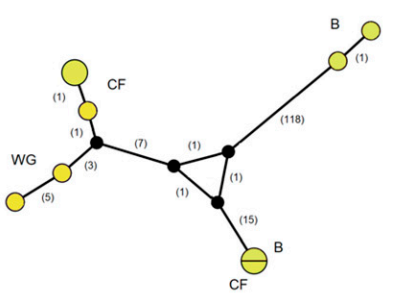

Figure 3. Cont. 

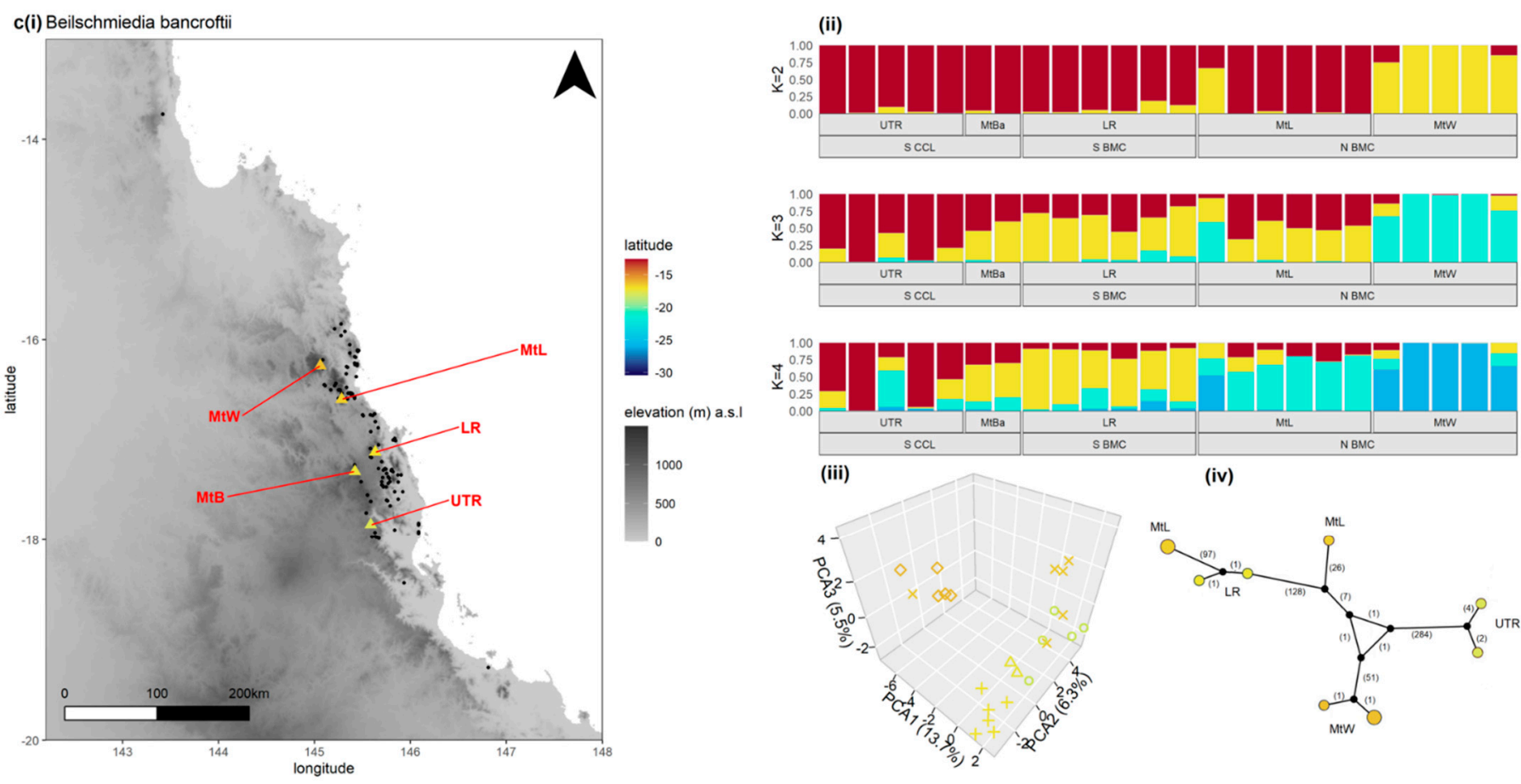

d(i) Planchonella australis

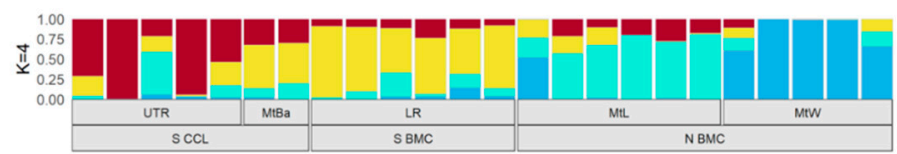

(iii)

(iv)
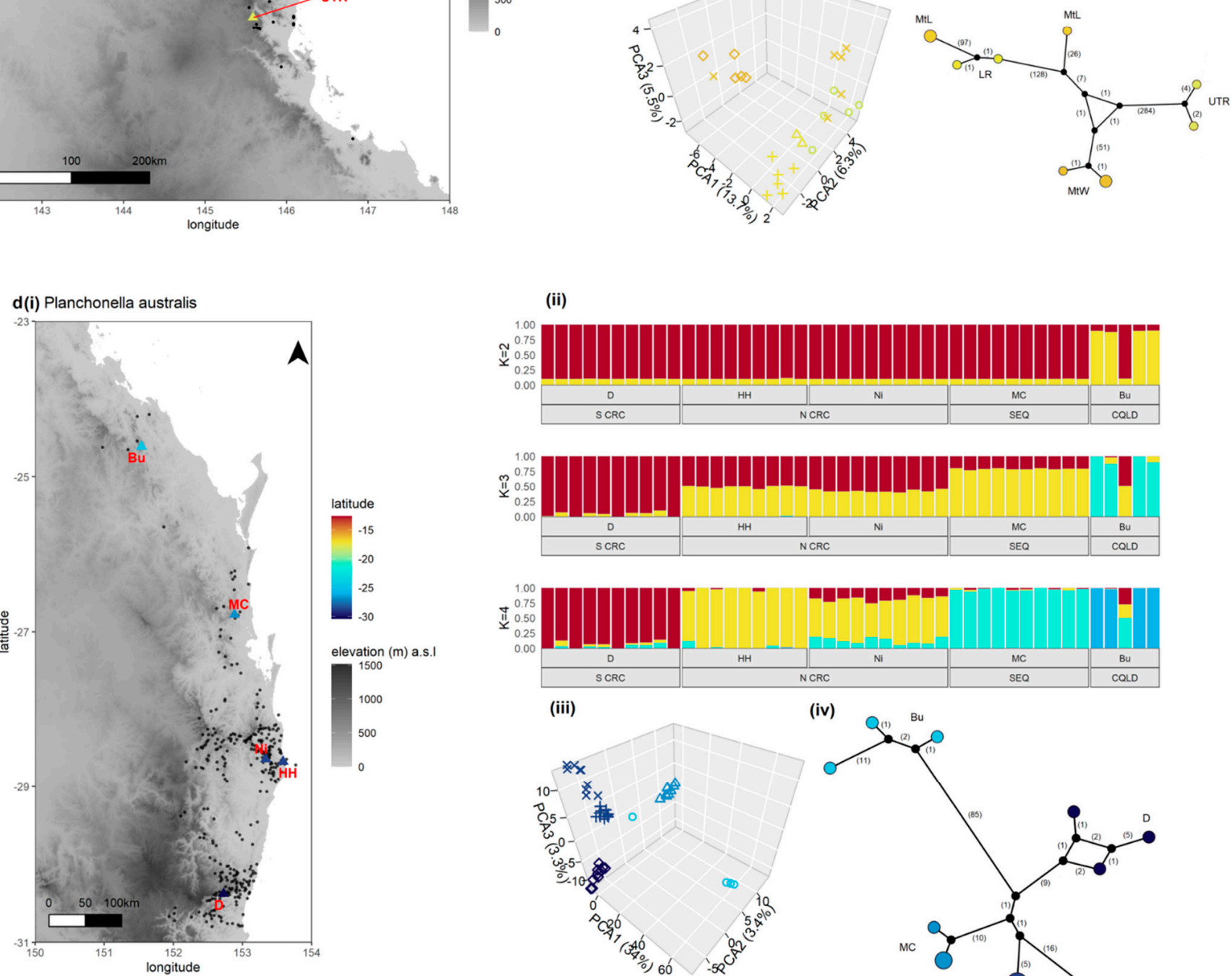

(ii)
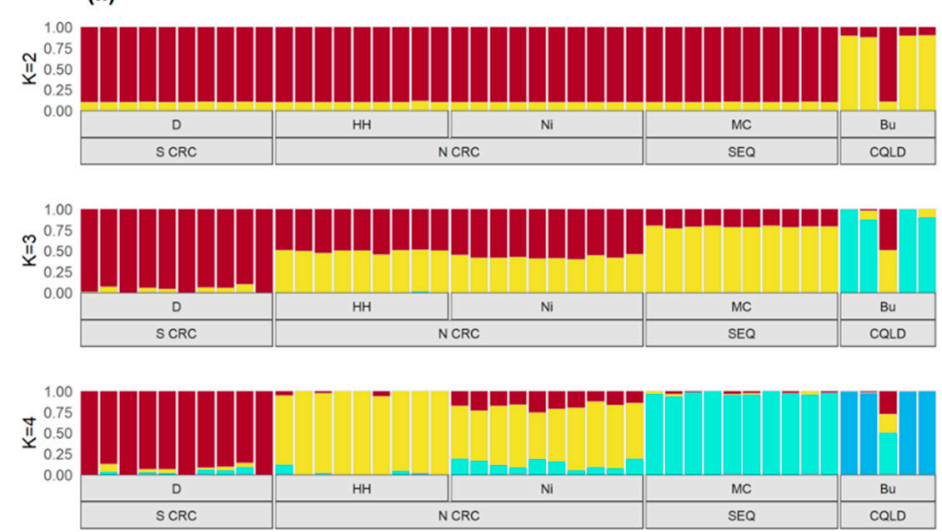

(iii)
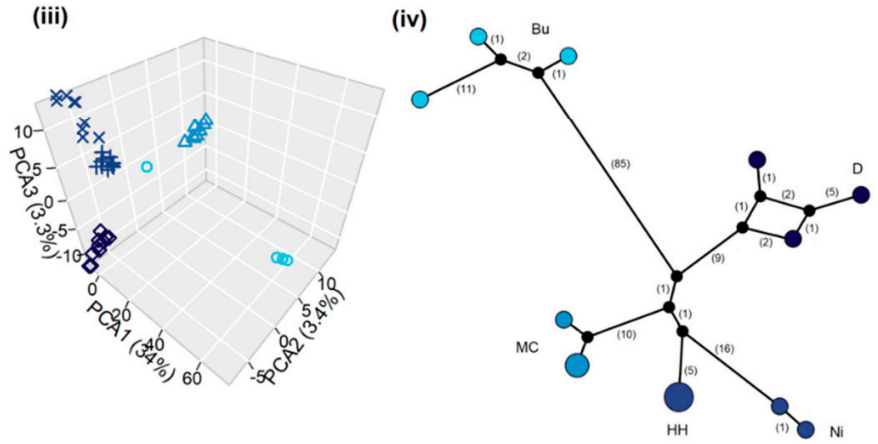

Figure 3. Cont. 

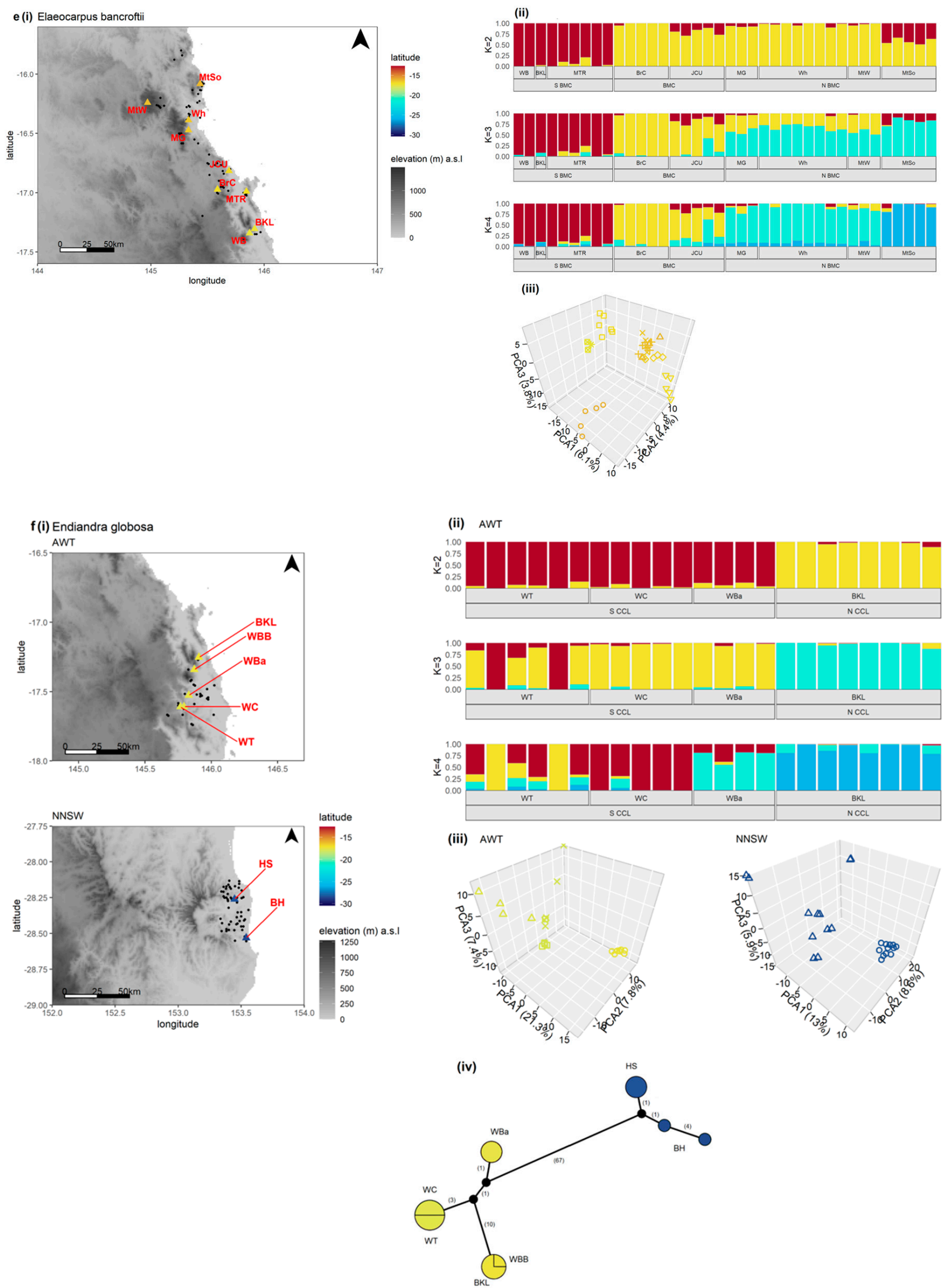

Figure 3. Cont. 
g(i) Endiandra compressa

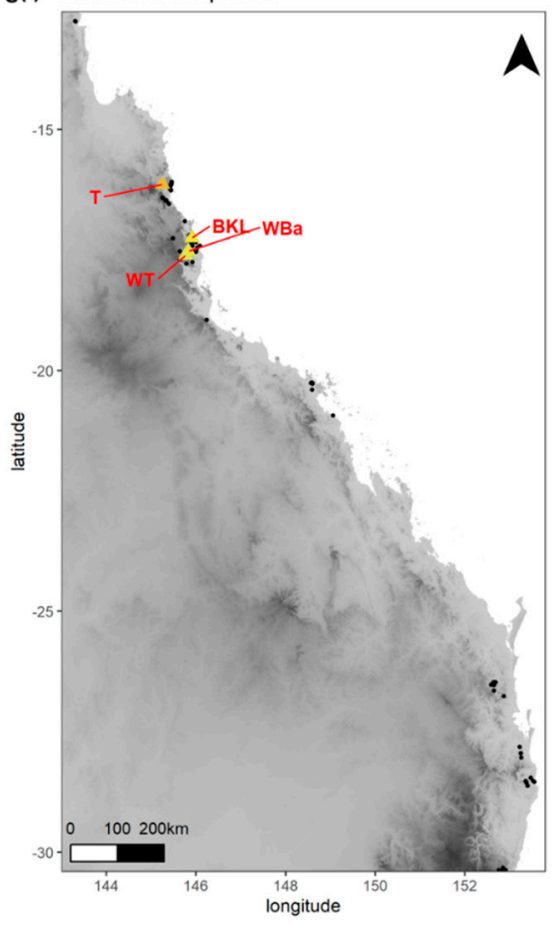

h(i) Endiandra pubens

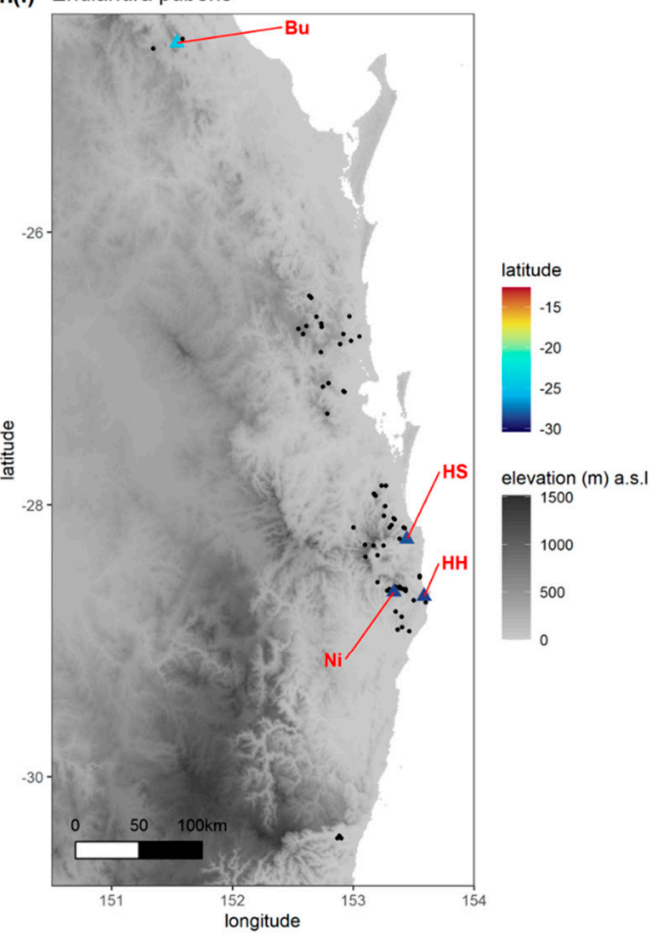

(ii)
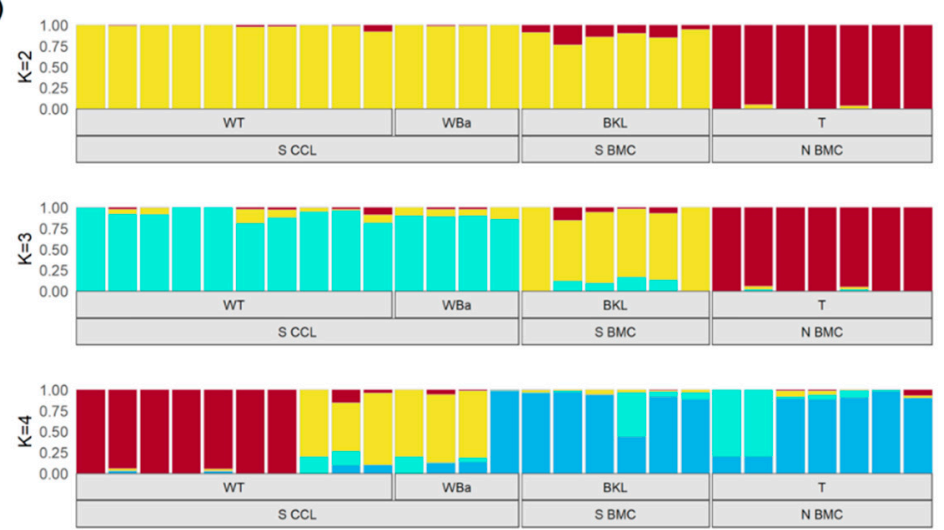

(iii)

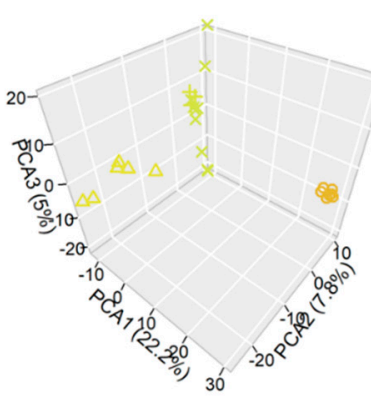

(iv)

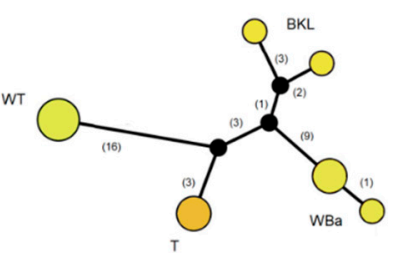

(ii)
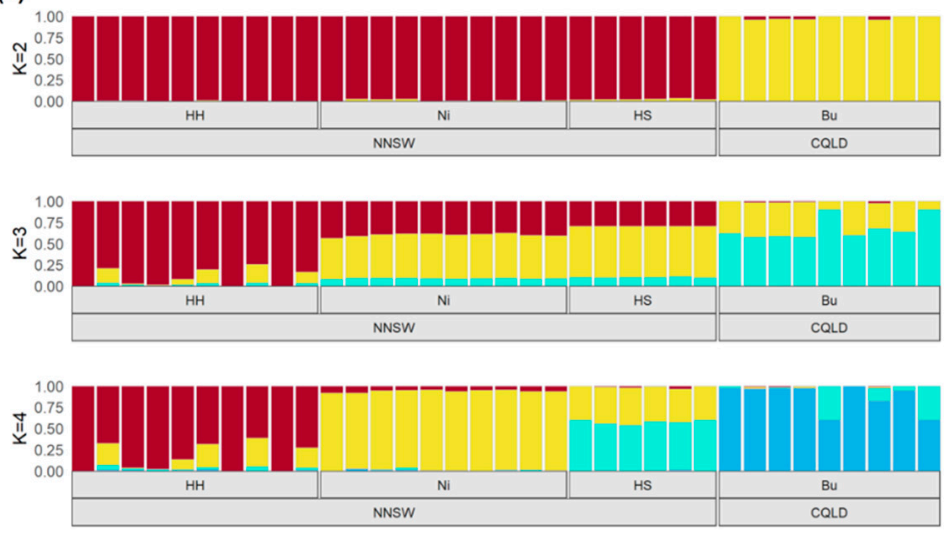

(iii)

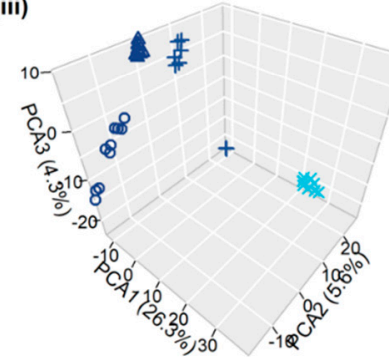

(iv)

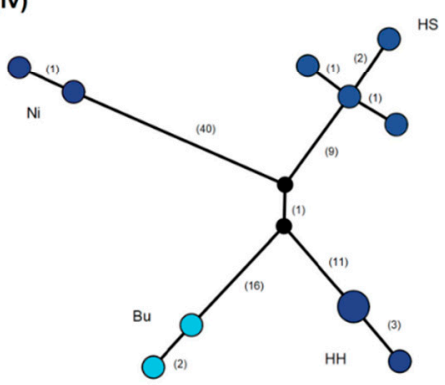

Figure 3. Cont. 

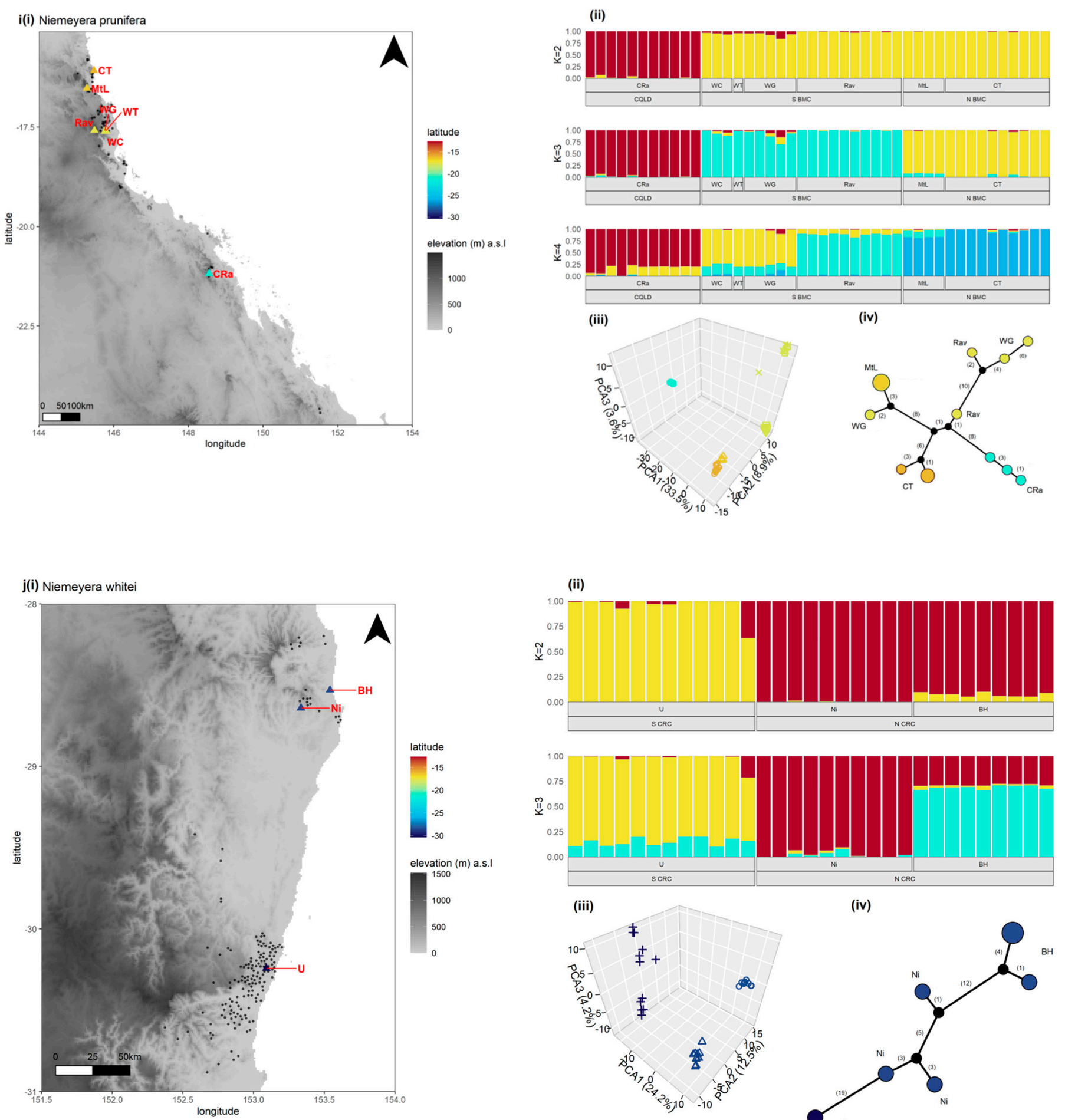

(iv)

Figure 3. Cont. 

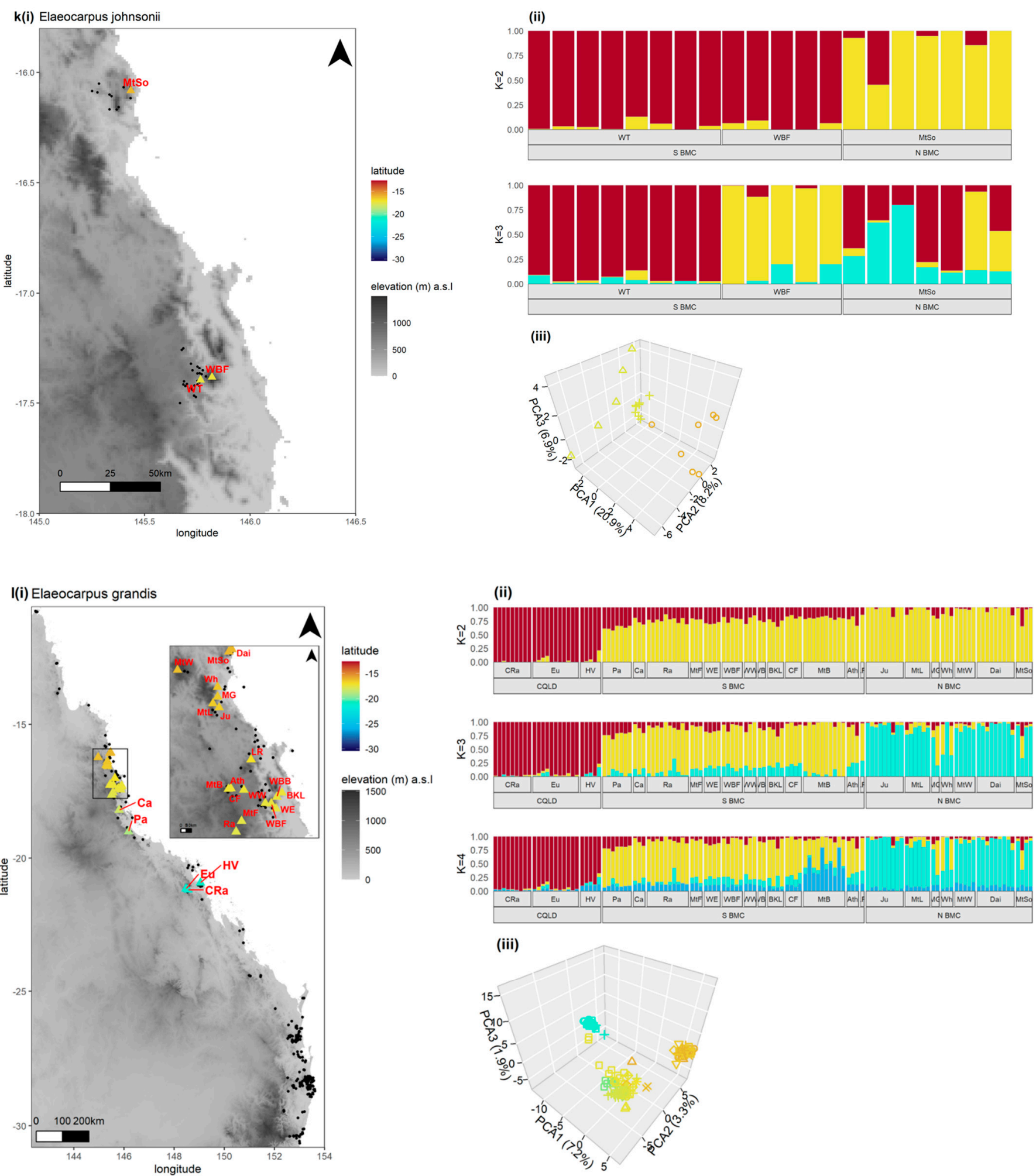

Figure 3. Cont. 

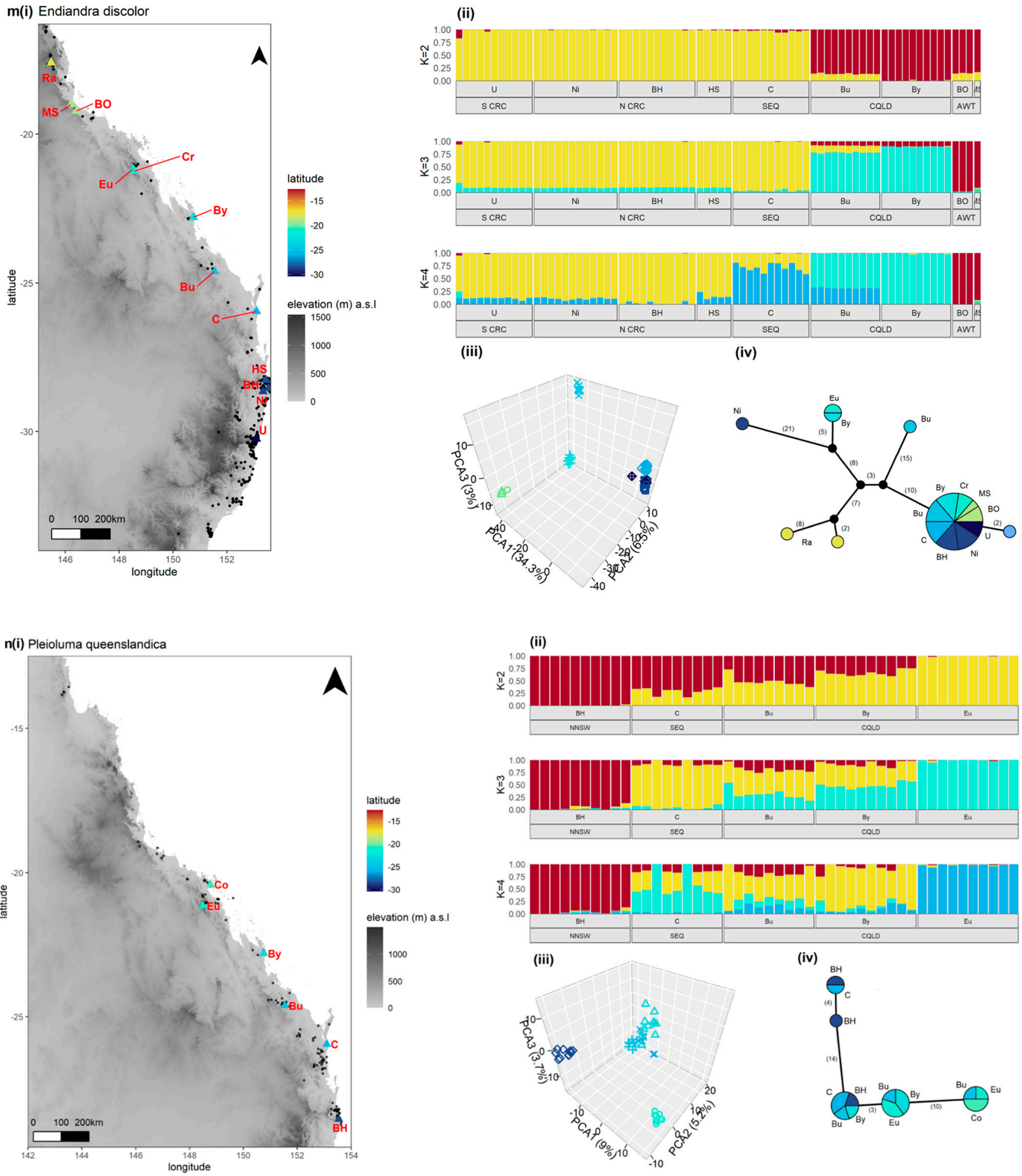

Figure 3. Cont. 

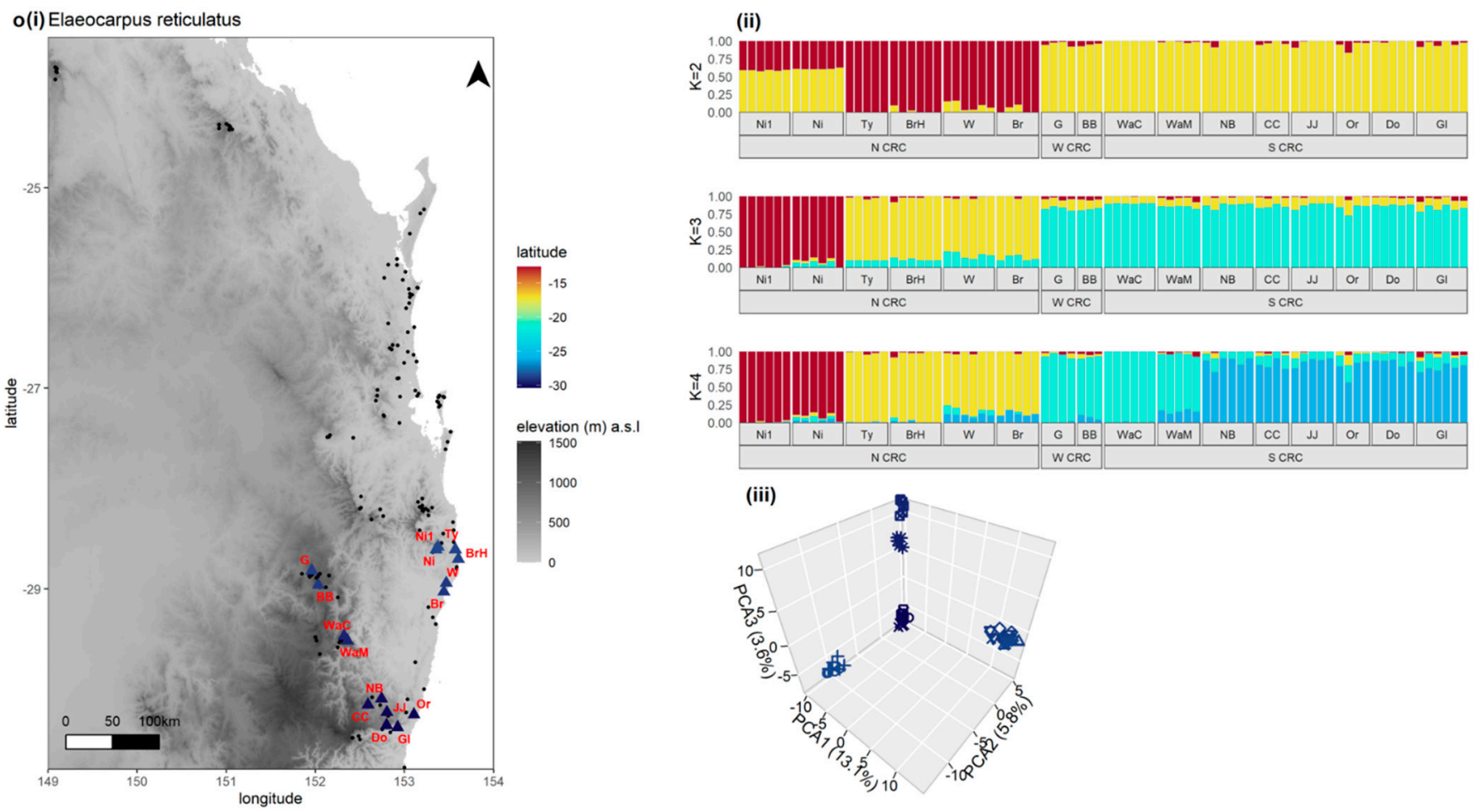

Figure 3. (a-o) The 15 study species evaluated for genomic signals of dispersal. For each species, (i) the distribution of the species in the study area is indicated by the black circles and the sample sites are coloured according to a latitudinal gradient defined by the extent of the study area. (ii) Genotype assignment proportions identified by sNMF, assuming $K=2-4$. The sample site and geographic region (or position in relation to a barrier) are indicated by the bottom panel. (iii) Principal components analysis of nDNA genomic variance between samples, ordinated by first three primary axes of variation. Samples are coloured according to latitude and shape indicates sample site. (iv) Median-joining network of chloroplast haplotypes (epsilon $=0$ ). Circles are proportional to the number of samples per haplotype and coloured by the latitude of the sample site. The number of mutations between haplotypes are in brackets, and the length of nodes are indicative but not directly proportional to number of mutations.

In the southern range, $C$. australe displayed two signals of dispersal that may be attributed to post-megafauna dispersal and presents a good candidate for further study (Table 3). First, we found low pairwise Fst values and a low Mantel correlate that suggests an absence of IBD consistent with recent or rapid migration (Signal 1; Table 2). The bestsupported sNMF models assumed $K=2-4$, though $K=4$ was most consistent with the PCA ordination (Figure S1 and Figure 3a(iv-v)). Both models show support for Signal 2, in which lowland sites (MP and Raz) have genomic profiles "admixed" between populations south of the CRC and upland sites north of the CRC. We did not find evidence of Signal 4 and the species shows unexpectedly strong structure between upland and lowland sites north of the CRC. This contrasts with the cpDNA results reported by Maurizio et al. (2017), which indicates widespread haplotype sharing in NNSW. The greater structure in the nDNA data may suggest that connectivity between sites has been lost in more recent generations.

E. insignis met one genomic signal of dispersal consistent with post-megafauna dispersal, though we identified it as a candidate for further study (Table 3). We did not find support for Signal 1, and E. insignis showed high Fst values, and a Mantel correlate consistent with IBD and limited faunal dispersal (Table 2). We did not find evidence of admixture between sites (Signal 2) and the best supported sNMF models ( $K=1-2$; Figure S1) revealed divergence across the CCL (Figure 3b(ii)). The PCA showed variation across the CCL and BMC (Figure $3 b(i i i)$ ). We found evidence of LDD in the cpDNA data (Signal 4) that contrasts with the nDNA patterns. The haplotype network suggests dispersal across the 
CCL with a shared haplotype at sites B and CF that is highly differentiated from the other samples at those sites (Figure $3 b(i v)$ ). This pattern is more consistent with recent migration between the two sites rather than an ancestral haplotype. The lack of nDNA evidence for LDD may suggest dispersal has ceased in more recent generations, allowing for nDNA diversity to accumulate between sites.

$B$. bancroftii showed genomic patterns consistent with three putative signals of postmegafauna dispersal, making the species a good candidate for further study (Table 3). First, we found support for Signal 1 with a combination of low Fst values and Mantel correlate, that suggests an absence of IBD and recent or rapid migration (Table 2). The best supported sNMF models assume $K=1-2$ (Figure S1) and together with the PCA reveal $B$. bancroftii is the only large-fruited species to show homogeneity among all sites excluding MtW (Figure 3c(ii-iii)). The PCA and sNMF also show one MtL sample clusters with MtW, potentially the outcome of LDD (Signal 3). The cpDNA data shows putative haplotype LDD (Signal 4) with one haplotype at MtL that is highly diverged from all others and may be a migrant from an unsampled population (Figure 3c(iv)). Alternatively, it may be a hybrid. Finally, the cpDNA network shows low variation within sites and high diversity between sites that suggests a long history of population isolation and bottlenecks. This is the opposite pattern to the nDNA data, suggesting that gene flow has shifted over time.

$P$. australis met only one signal of dispersal (Table 3) and is not considered a candidate for further study. We found low pairwise Fst values and a Mantel score that corresponds with IBD, consistent with long-term faunal connectivity (Table 2). The best supported sNMF model $(K=2$; Figure S1) and the PCA show the primary source of variation is across the Wide Bay-Burnett region (WBB) in CQLD, and there is low variation albeit latitudinal structure between populations south of the barrier (Figure 3d(ii-iii)). One sample from CQLD has a genotype that clusters with the populations south of WBB suggesting past or recent LDD (Signal 3). The cpDNA network shows high variation consistent with vicariance across WBB and moderate haplotype diversity within and between the southern populations (Figure 3d(iv)). These patterns match that of the nDNA data and together suggest long-term population stability and periodic isolation rather than rapid migration and range expansion that we would expect of extensive Holocene faunal or anthropogenic dispersal. There is no cpDNA available for the CQLD sample that showed southern ancestry in the nDNA data, so it is unclear if the sample is a recent migrant.

E. bancroftii showed genomic patterns consistent with two signals of post-megafauna dispersal, and we considered it a candidate for further studies (Figure 1). We found support for Signal 1 with a combination of low pairwise Fst values and the absence of IBD, suggesting rapid migration (Table 3 ). The best supported sNMF model assumes $K$ $=1$ (Figure S1), and there is weak population structure in the PCA, primarily across the CCL (Figure 3e(ii-iii)). The $K=3$ sNMF model is most concordant with the PCA and shows mixed genotypes that suggest admixture or ILS between sites within and north of the BMC (Signal 2. We did not have cpDNA data for this species, and so could not test for Signal 4.

\subsubsection{Large Fruit with Unknown Indigenous Use}

We assessed E. globosa in the AWT and NNSW separately, due to the large geographic and genetic disjunction between the two regions. In the AWT, the genomic patterns in E. globosa were consistent with only one signal of dispersal (Figure 1). We found high pairwise Fst values over short distances that correspond with IBD, suggesting long-term isolation (Table 3). The best supported sNMF model ( $K=3$; Figure S1) and PCA revealed structure across the CCL, and outlier genotypes in WT potentially indicative of LDD (Signal 3; Figure 3f(ii-iii)). The cpDNA data are mostly concordant with the nDNA patterns and show haplotype divergence across the CCL and haplotype sharing between neighbouring sites (Figure 3f(iv)).

As there were only two E. globosa sites sampled in NNSW, we could not perform the Mantel or sNMF analyses for this region. We found E. globosa in NNSW matched one signal of dispersal and we did not consider it a candidate for further study (Figure 1). 
According to the PCA, most variation is between sites though there are outlier samples in HS, suggesting LDD (Signal 3; Figure 3f(iii)). The cpDNA shows the opposite trend to the nDNA data, with greater haplotype variation within $\mathrm{BH}$ and low variation between sites (Figure 3f(iv)). However, we did not find evidence of haplotype dispersal (Signal 4).

E. compressa did not show any genomic patterns consistent with dispersal and was not considered for further study (Table 3). We found high Fst values, and a high Mantel correlate consistent with limited faunal dispersal (Table S2 and Table 3). The primary source of variation was across the BMC according to the best supported sNMF model $(K=2$; Figure $\mathrm{S} 1)$ and PCA ordination, though there is some structure across the CCL (Figure $3 \mathrm{~g}(\mathrm{iii})$ ). The cpDNA network contrasts with the nDNA patterns and shows greater divergence between geographically proximate sites south of CCL while differentiation across the BMC is comparatively low (Figure $3 g$ (iv).

The genomic patterns in E. pubens did not match any signals of dispersal and was not considered for further study (Figure 1). The populations in NNSW have moderate pairwise Fst values and a Mantel score consistent with IBD rather than rapid migration (Table 2). The best supported SNMF model $(K=2$; Figure S1) and PCA reveal divergence between NNSW and CQLD (Figure 3h(ii-iii)). The PCA shows one outlier sample from NNSW, that may indicate LDD; however, this is not evident in the sNMF models. The cpDNA network conflicts with the nDNA data and shows greater variation within NNSW than between regions (Figure $3 \mathrm{~h}(\mathrm{iv})$ )).

We found only one genomic signal of dispersal in N. prunifera though we regard it as a candidate for investigation of Indigenous dispersal (Table 3). We did not find support for Signal 1 and N. prunifera has moderate pairwise Fst values and a high Mantel correlate that suggests IBD. The best supported sNMF model $(K=3$; Figure S1) and PCA show differentiation between CQLD and the AWT and across the BMC, though no evidence of outliers or admixture (Figure 3i(ii-iii)). The cpDNA network displays high diversity within populations and only moderate differentiation between populations (Figure 3i(iv)). The relationships between some haplotypes are not geographically concordant and are consistent with LDD (Signal 4), including across the BMC. There is weaker population structure in the cpDNA compared with the nDNA data and may suggest past rapid migration followed by a decrease in dispersal over time.

$N$. whitei did not correspond with any signals and we did not consider it a candidate for further study (Table 3). We found high pairwise Fst values that correspond moderately with IBD, consistent with limited faunal dispersal (Figure S1; Table 2). The best supported sNMF model ( $K=3$; Figure S1) shows admixture or ILS, though this is not evident in the PCA clusters (Figure 3j(ii-iii)). The cpDNA network is concordant with the nDNA structure across the CRC, and the high variation suggests it is a long-term barrier (Figure 3j(iv)).

We found one signal of dispersal within E. johnsonii and did not consider it for further study (Table 3). The species has low to moderate Fst values, and a Mantel result consistent with IBD and long-term faunal dispersal (Table 2). The best supported sNMF model (K = 2; Figure S1) and PCA ordination show most variation is across the BMC and within sites (Figure 3k(ii-iii)). Both models indicate one MtSo sample has a mixed genotype that clusters with populations both sides of the BMC suggesting past LDD across the barrier (Signal 3). We did not have cpDNA data available to test for Signal 4.

\subsubsection{Small Fruit with Known History of Indigenous Use}

E. grandis has genomic patterns that match two signals of dispersal, though we do not consider it a candidate for further study as we could not eliminate the influence of faunal vectors (Table 3). We performed separate Mantel tests for north and south of the BMC. To the south, we found low Fst values, and a low Mantel correlate consistent with rapid migration (Signal 1). North of the BMC, low Fst values combined with a moderate Mantel score consistent with IBD driven by widespread faunal dispersal (Table S2 and Table 2). The best supported sNMF model ( $K=3$; Figure S1) is concordant with the PCA (Figure 31(ii-iii)). Both analyses identified three relatively homogeneous population clusters separated by 
the $\mathrm{BMC}$ and a $2^{\circ}$ latitudinal disjunction to the south, consistent with extensive regional faunal dispersal. The models also show four samples from north of the BMC cluster with populations south of the barrier, potentially indicating LDD (Signal 3).

\subsubsection{Small Fruit with Unknown Indigenous Use}

The genomic patterns in E. discolor align with two signals of dispersal; however, the species was not considered a candidate for further study as it showed patterns more consistent with widespread faunal dispersal (Table 3). We performed a Mantel test in NNSW only, as the other sites were too disjunct for a meaningful analysis. We found low pairwise Fst values and a very low Mantel score that suggests rapid migration consistent with Signal 1, though this is likely facilitated by widespread faunal dispersal (Table S2 and Table 2). Each of the sNMF models are equally supported and $K=4$ shows admixed profiles between NNSW-SEQ and SEQ-CQLD, consistent with Signal 2 (Figure S1; Figure 3m(ii)). However, given SEQ and CQLD cluster separately in the PCA (Figure 3m(iii)), incomplete lineage sorting is more plausible than admixture. In the chloroplast haplotype network, E. discolor has one widespread haplotype distributed from the AWT to NNSW and some unique northern haplotypes differentiated along a latitudinal gradient (Figure $3 \mathrm{~m}(\mathrm{iv})$ ). This pattern may be attributed to Indigenous dispersal (Signal 4), though it is consistent with the nDNA data and more likely suggests periods of isolation across latitudinal barriers and subsequent widespread re-connectivity.

The patterns we found in P. queenslandica were consistent with long-term faunal dispersal and the species was not considered a candidate for further study (Table 3). We found low pairwise Fst values across more than $7^{\circ}$ of latitude (Table S2), though we had insufficient samples to test IBD within regions. The best supported sNMF models $(K=1-2$; Figure S1) and PCA ordination show clinal variation in CQLD consistent with admixture or ILS between a northern and southern genotype (Signal 2; Figure 3m(ii-iii)). The cpDNA network shows range-wide haplotype sharing with moderate variation between haplotypes (Figure 3g). This may be attributed to Indigenous dispersal (Signal 4), though it is consistent with the nDNA data and more likely suggests a stable history of gene flow rather than LDD.

We did not find any genomic signals in E. reticulatus and it was not considered for further investigation of Indigenous dispersal (Table 3). We found high pairwise Fst values that moderately correlate with IBD (Table 2$)$. The best supported sNMF model $(K=3$; Figure S1) and the PCA ordination show the primary variation is across the CRC (Figure 3o(ii-iii). There is also variation between coastal and upland sites north of the barrier and between the sites west and south of the barrier.

\section{Discussion}

Reconstructing the demographic history of non-domesticated species with coalescent models can be a costly and challenging endeavour that requires extensive sampling and/or deep sequencing. Therefore, we sought to develop a simple and cost-effective screening strategy that can be used to screen out species with genomic patterns consistent with longterm widespread faunal dispersal and identify "candidate" species that show dispersal signals that warrant further investigation. The genomic signals we found in C. australe confirm the utility of our workflow, in which extensive Indigenous dispersal has already been demonstrated [32]. Our findings demonstrate that fast and widely used population genomic analyses can be employed to identify candidate species from opportunistically collected and somewhat sparse sample sets. Another advantage of our approach is that the genomic tests did not require any assumptions about the biogeographic history of the study species, making it a good first step. Our approach can be replicated in other study systems that have undergone a megafauna extinction and where Indigenous dispersal has been recorded.

We identified five candidates out of 15 species that show interesting dispersal patterns of putative Indigenous influence. Neither of the large-fruited study species displayed signals of ongoing or widespread dispersal. This raises the hypothesis that prior to putative 
Indigenous dispersal events within the candidate species, there was a considerable period of isolation driven by the megafauna extinction. As a next step, coalescent analyses can be used to estimate the antiquity of dispersal events. Based on the genomic patterns we found, we have suggested some hypothetical scenarios of past Indigenous dispersal to explore for each candidate (Table 4). Candidates can be co-analysed with ecologically similar and co-distributed species to contrast the influence of Indigenous versus faunal dispersal.

An important underpinning of our screening strategy was to eliminate faunal vectors (or other non-anthropogenic vectors) as the sole mode of dispersal within candidate species. To test the efficacy of our approach, we compared simulated and real genomic datasets of large- and small-fruited species with edible fruit. Most of the candidates we identified are large-fruited species with a known history of Indigenous use and carry signals of dispersal that are distinctive from widespread faunal dispersal. Likewise, the results of our simulation study demonstrate that long-term, range-wide faunal dispersal scenarios expected of small-fruited species yield patterns of population differentiation that are clearly distinct from species with a history of post-megafauna isolation followed by Indigenous dispersal.

Our findings confirm that dispersal-limited plants are more likely to carry genomic signatures that are suitable for investigating past Indigenous dispersal. First, we used pairwise genetic distance estimates to demonstrate that the large-fruited study species are more dispersal limited than the small-fruited and wind-dispersed species. Then, in the screening process, we found that the barrier effects evident in large-fruited species made distinctive signals of dispersal more apparent, particularly putative signals of LDD (Signal 3-4). Interestingly, we did not detect an overall trend of greater gene flow in the AWT (where a larger cohort of faunal dispersers still survives) compared with NNSW.

By the same token, we found that small-fruited species are generally less suitable for investigating Indigenous dispersal. Given their small fruit size, it is difficult to differentiate the relative influence of humans from volant frugivores or other natural dispersal vectors. For instance, widespread haplotype sharing in P. queenslandica and E. discolor may be attributed to Indigenous dispersal, though it is more consistent with faunal-mediated post-glacial recolonisation. Meanwhile, Elaeocarpus grandis and P. australis continue to be well-utilised by various Aboriginal groups and show nDNA signals of LDD. However, $P$. australis shows CpDNA structure more consistent with long-term isolation than extensive faunal- or Indigenous-mediated dispersal. In the case of E. grandis, rainforest restoration activities over the past few decades may also confound dispersal signals.

Out of all the candidates, N. prunifera is the only species for which we could not find any literature or verbal reports of use by Indigenous groups. The patterns we found for this species highlights the utility of genomic tests to investigate historical Indigenous dispersal, even in the absence of strong ethnographic evidence. On the other hand, we identified E. globosa as a poor candidate for Indigenous dispersal studies, despite archaeological evidence that the seed of morphologically similar and closely related Laurels were processed and consumed during the late Holocene [71,72]. It is worth noting that seed biology may prohibit successful attempts at long-distance dispersal of some food trees, as the seed of many Australian rainforest species do not store well and would not survive long journeys [84]. 
Table 4. Candidate species that warrant investigation of historical Indigenous dispersal and suggested follow up studies. Species were identified as candidates if they displayed at least one of five genomic signals of dispersal that can be tested as anthropogenic vs. non-anthropogenic in future studies, and generated hypotheses on Indigenous dispersal scenarios. We considered species as weak candidates if they displayed genomic patterns from which putative Indigenous dispersal could not be differentiated from widespread faunal dispersal or if they showed an absence of dispersal events.

\begin{tabular}{ll}
\hline Species & \multicolumn{1}{c}{ Dispersal Hypotheses } \\
\hline & (a) $\begin{array}{l}\text { During the Holocene, C. australe was } \\
\text { introduced to NNSW from a single } \\
\text { northern lineage by humans or oceanic } \\
\text { currents, and/or humans rapidly ex- } \\
\text { panded its range in the region. } \\
\text { Extensive human-dispersal pathways } \\
\text { in NNSW disrupted natural patterns of } \\
\text { IBD evident in the north. } \\
\text { Upland populations in NNSW were es- } \\
\text { tablished by humans. Founder effects } \\
\text { and/or a subsequent lack of gene flow } \\
\text { into these populations has led to drift. }\end{array}$ \\
& (b)
\end{tabular}

(a) Sample upland sites and multiple lowland sites in multiple catchments across the species' distribution, including CQLD.

(b) Whole-genome sequencing for phased dataset that can be used to identify the geographic distribution of identity-bydescent blocks and recent coalescent events. Select population samples within each region to date the arrival of $C$. australe in NNSW and test for recent co-ancestry with northern genotypes.

(c) Employ directional migration models between catchments to verify non-water modes of dispersal and test putative human-dispersal pathways inferred from ethnographic sources.

(d) Employ directional migration models within catchments to verify that connectivity has been lost at upland sites.

(a) Sample additional populations at Atherton where there is archaeological evidence of E. insignis seed processing, and east along ancient walking routes between the Atherton Tableland and the coast.

(a) Mid-late Holocene human-mediated dispersal between two previously isolated sites, B and CF.

E. insignis

(b) Holocene propagation along ancient walking routes between Atherton Tableland and the coast.

(c) A subsequent decline or loss of dispersal has led to drift between populations.

(b) To investigate dispersal across the BMC and between isolated upland sites, sample additional sites north of the BMC and at southern part of the range near the most differentiated population at site $B$.

(c) Coalescent isolation with migration model to test for preHolocene vicariance between Bolinda and Curtain Fig, followed by Holocene-era LDD.

(a) Following megafauna decline, a long history of isolation has driven extreme haplotype differentiation between sites. Bottlenecks have reduced nDNA diverB. bancroftii sity and overall differentiation between sites.

(b) Reinforcement-Holocene-era Indigenous dispersal facilitated limited migration between sites.

(a) Additional cp-sequencing per population to identify further evidence of dispersal events.

(b) Isolation with migration coalescent models to test hypothesis of long-term vicariance followed by recent Indigenousfacilitated migration between sites.

(a) Rapid dispersal along cultural rather than geographic pathways.

E. bancroftii (b) Reinforcement-Holocene-era Indigenous dispersal facilitated limited migration and admixture across the BMC.

(a) Cp-sequencing to better infer dispersal between sites.

(b) Coalescent model to evaluate ILS versus admixture between populations across the BMC.

(a) Mid-late Holocene human-mediated LDD explains the disjunct distribution of $N$. prunifera in the AWT and CQLD and the migration of cp-haplotypes between geographically distant sites.

(b) A subsequent decline or loss of dispersal has led to drift and strong nDNA structure.

(a) Sample additional populations in southern AWT to investigate the likelihood of vicariance versus LDD as the cause of disjunct distribution between AWT and CQLD.

(b) Coalescent analysis to date divergence between AWT and CQLD. Divergence < 10 kya is likely human LDD, > 21 kya is likely climate-driven vicariance.

(c) Test for founder effects in CQLD, as support for LDD. 


\section{Conclusions}

Overall, the workflow we have presented enabled us to identify genomic signals of dispersal that may be attributed to the past influence of Indigenous peoples and can be differentiated from widespread faunal dispersal. This includes species with edible fruit that lack published ethnographic evidence of Indigenous use. We found that the utilisation of both nDNA and cpDNA data was important for detecting putative dispersal signals, and its absence from the Elaeocarpus datasets made it more difficult to assess these species. We also found that three cpDNA samples per site was not always sufficient to identify dispersal events, and more samples would have aided interpretation where evidence of LDD was found in the nDNA. Therefore, we recommend that future screening studies utilise cpDNA sequence data for all samples.

Supplementary Materials: The following are available online at https:/ /www.mdpi.com/article/10 .3390 /genes13030476/s1, Figure S1: Cross-entropy criterion plotted against the number of ancestral gene pools $(K)$ used to construct sNMF models. The smallest criterion was used to help assess the model that best described the genomic variance within each species; Table S1: Meta data for the study species [88]; Table S2: Pairwise genetic and geographic distance values used to calculate each species' Mantel score and construct violin plots of average pairwise Fst estimates amongst species grouped by fruit traits.

Author Contributions: Conceptualization, M.R. and M.F.; data acquisition, A.F.; formal analysis, M.F.; writing—original draft preparation, M.F.; writing—review and editing, M.R. and E.E.; visualization, M.F.; supervision, M.R. and E.E.; project administration, E.E.; funding acquisition, E.E. All authors have read and agreed to the published version of the manuscript.

Funding: This research was funded by the Australian Research Council, grant number DP180102188.

Data Availability Statement: The genomic datasets used in this study are available from the link (https: / / doi.org/10.5061/dryad.m0cfxpp5h) accessed on 2 March 2022.

Acknowledgments: The authors would like to acknowledge Jason Bragg for providing scripts written in R code to filter, organise and analyse the DArTseq data used in some of the analyses for this study.

Conflicts of Interest: The authors declare no conflict of interest. The funders had no role in the design of the study; in the collection, analyses, or interpretation of data; in the writing of the manuscript, or in the decision to publish the results.

\section{Appendix A. Simulation Study to Compare the Genomic Signals of Hypothetical Indigenous versus Faunal-Mediated Dispersal Scenarios}

\section{Appendix A.1. Materials \& Methods}

We used fastsimcoal $2.7[85,86]$ to simulate 9 hypothetical dispersal scenarios for species with a history of long-term isolation (1 model), long-term faunal mediated dispersal ( 2 models), or Indigenous dispersal following long-term isolation (6 models). To compare the genomic impact of dispersal traits on population differentiation, we constructed models that varied only in the timing and pattern of historical migration events (see Table A1 for model parameters and figure captions for interpretation). The migration rate (Nm) specified at each historical event are outlined in Table A2. Each model was simulated with 100 replicates.

The demographic models assume a 110 ky cycle of habitat suitability that approximates the climatic history of the Australian continent. We simulated high migration rates and population growth during warm-wet periods (110 kya and 5-9 kya), moderate migration rates and population growth during inter-glacial periods (9-18 kya, 40-60 kya, 70-110 kya), and no migration with a population bottleneck during glacial periods (60-70 kya and 18-25 kya). All models consist of 6 demes with an effective population size (Ne) of 400 with population growth $=0$, and we sampled 20 diploid individuals per deme. This excludes the models that simulate mid-Holocene range expansion, in which deme 0 has $\mathrm{Ne}=200$ and originates from deme1. 
To simulate independent unlinked SNP loci analogous to DArTseq, we followed the procedure recommended by Excoffier et al. (2021) [86] to generate short DNA sequences over a large number of chromosomes that are only mutate via transitions (transition rate $=1$ ). Under a finite-site mutation model, genes were simulated across 240 chromosomes that each contain 200 DNA sequence linkage blocks $(100 \mathrm{bp})$. We fixed the recombination rate to $1.0 \times 10^{-9}$ and the mutation rate to $2.0 \times 10^{-8}$. We selected these values to ensure there were no recombination events and a maximum of one mutation per loci. For each scenario, we simulated historical events assuming a 20-year and 40-year generation time $(\mathrm{t}=$ absolute time/generation time).

We calculated pairwise Fst values (Slatkin's distance) from the output of each simulation with 100 permutations $(p=0.05)$ in Arlequin 3.5.2.2 [87].

Table A1. Historical events that determine coalescence under 9 dispersal scenarios. The first three columns indicate the time of historical events in years or generations before present assuming a 20 year and 40 year generation time ("gen20" and "gen 40 "). Fission between demes was used to simulate rapid range expansion events. Going backwards in time, the "source" is the deme from which genes originate, "sink" is the deme to which they go, and " $\mathrm{m}$ " indicates the percentage of genes in the sink that originate from the source $(1=$ all genes). Ne is re-scaled by "size" at each historical event and by the "growth rate" per generation until the next event (negative values imply population expansion backwards in time). The migration matrix at each historical event is indicated for each dispersal scenario. $\mathrm{fd}=$ post-glacial faunal dispersal, $\mathrm{fd}+\mathrm{exp}=$ post-glacial faunal dispersal and range expansion, nd $=$ post-megafauna isolation, hd1 $-6=$ post-megafauna Indigenous dispersal scenarios .

\begin{tabular}{|c|c|c|c|c|c|c|c|c|c|c|c|c|c|c|c|c|}
\hline \multirow[b]{2}{*}{ Years } & \multirow[b]{2}{*}{ gen20 } & \multirow[b]{2}{*}{ gen40 } & \multirow[b]{2}{*}{ Source } & \multirow[b]{2}{*}{ Sink } & \multirow[b]{2}{*}{ m } & \multirow[b]{2}{*}{ Size } & \multirow[b]{2}{*}{ Growth Rate } & \multicolumn{9}{|c|}{ Migration Matrix according to Dispersal Scenarios } \\
\hline & & & & & & & & fd & $f d+\exp$ & nd & hd1 & hd2 & hd3 & hd4 & hd5 & hd6 \\
\hline 0 & 0 & 0 & 0 & 0 & 0 & 1 & 0 & 0 & 0 & 2 & 2 & 2 & 2 & 2 & 2 & 2 \\
\hline 200 & 10 & 5 & 0 & 0 & 0 & 1 & -0.02 & - & - & - & 6 & 6 & - & - & 7 & - \\
\hline 3999 & 199 & 99 & 0 & 0 & 0 & 1 & -0.02 & - & - & - & - & - & 6 & - & - & - \\
\hline 4000 & 200 & 100 & 0 & 0 & 0 & 1 & -0.02 & - & - & - & - & - & - & - & - & 7 \\
\hline 4999 & 249 & 124 & 0 & 1 & 1 & 1 & -0.02 & - & - & - & - & 6 & 2 & 2 & - & - \\
\hline 5000 & 250 & 125 & 0 & 0 & 0 & 1 & -0.02 & 1 & 1 & 2 & 2 & 2 & 2 & 2 & 2 & 2 \\
\hline 6000 & 300 & 150 & 0 & 1 & 1 & 1 & -0.02 & - & 1 & - & - & - & - & - & - & - \\
\hline 9000 & 450 & 225 & 0 & 0 & 0 & 1 & -0.005 & 0 & 0 & 2 & 2 & 2 & 2 & 2 & 2 & 2 \\
\hline 18,000 & 900 & 450 & 0 & 0 & 0 & 0.5 & 0.02 & 2 & 2 & 2 & 2 & 2 & 2 & 2 & 2 & 2 \\
\hline 25,000 & 1250 & 625 & 0 & 0 & 0 & 1 & 0.005 & 3 & 3 & 2 & 2 & 2 & 2 & 2 & 2 & 2 \\
\hline 40,000 & 2000 & 1000 & 0 & 0 & 0 & 1 & -0.005 & 0 & 0 & 2 & 2 & 2 & 2 & 2 & 2 & 2 \\
\hline 60,000 & 3000 & 1500 & 0 & 0 & 0 & 0.5 & 0.02 & 2 & 2 & - & 2 & 2 & 2 & 2 & 2 & 2 \\
\hline 70,000 & 3500 & 1750 & 0 & 0 & 0 & 1 & -0.005 & 0 & 0 & 4 & 4 & 4 & 4 & 4 & 4 & 4 \\
\hline 110,000 & 5500 & 2750 & 0 & 0 & 0 & 1 & -0.02 & 1 & 1 & 5 & 5 & 5 & 5 & 5 & 5 & 5 \\
\hline
\end{tabular}

Table A2. Migration matrices employed in simulation models.

\begin{tabular}{llll}
\hline Matrix & Migration & Nm & Dispersal Vector \\
\hline 0 & Symmetric distance-weighted migration with barrier between deme2 & $0.0005,0.0002,0.0000$ & Volant fauna \\
& and deme3 & $0.0200,0.0100,0.0050$, & Volant fauna \\
1 & High symmetric distance-weighted migration with no barrier & $0.0025,0.0012$ & NA \\
2 & No migration & 0.0000 & Volant fauna \\
3 & Low symmetric distance-weighted migration with barrier between & $0.0025,0.0012,0.0000$ & Megafauna \\
4 & deme2 and deme3 & $0.0050,0.0000$ & Megafauna \\
5 & Symmetric stepping-stone with barrier between deme2 and deme3 & $0.0200,0.0000$ & Human \\
6 & High symmetric stepping-stone migration with no barrier & 0.0025 & Human \\
7 & Low asymmetric stepping-stone migration & 0.0025 & \\
\hline
\end{tabular}


Appendix A.2. Results

post-glacial faunal dispersal

generation time $=20$

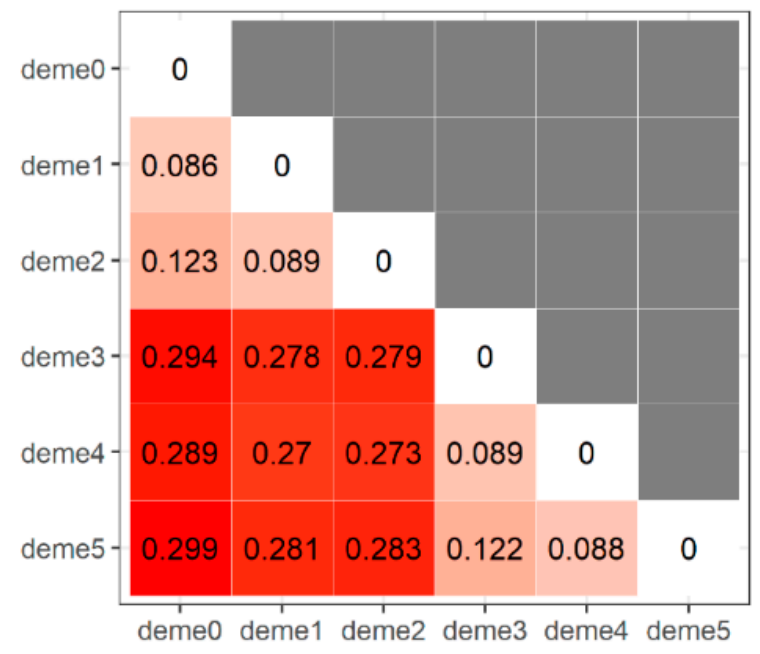

generation time $=40$

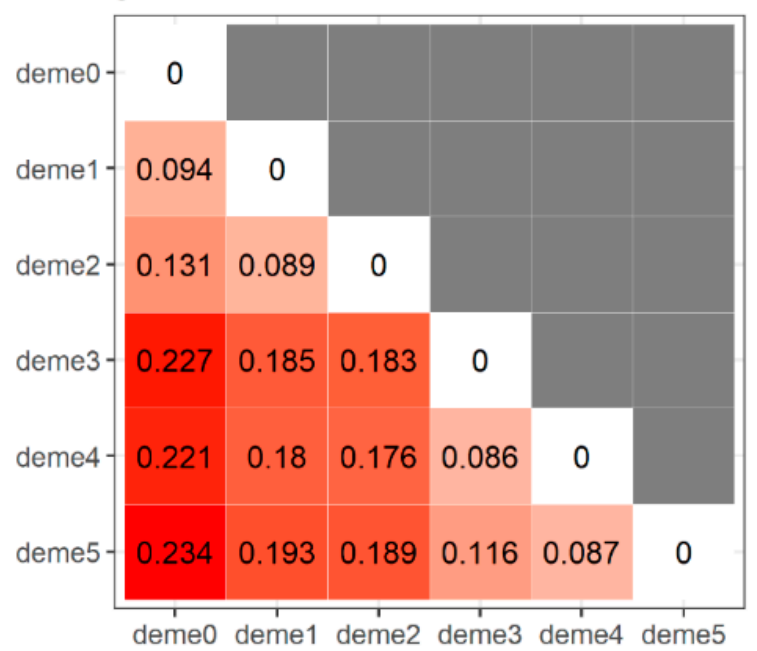

Figure A1. The mean pairwise Fst values calculated across 100 replicate simulations of a post-glacial faunal-mediated dispersal scenario ("fd" in Table A1). This scenario of faunal dispersal assumes a symmetric distance-weighted migration matrix.

\section{post-glacial faunal dispersal \& range}

generation time $=20$

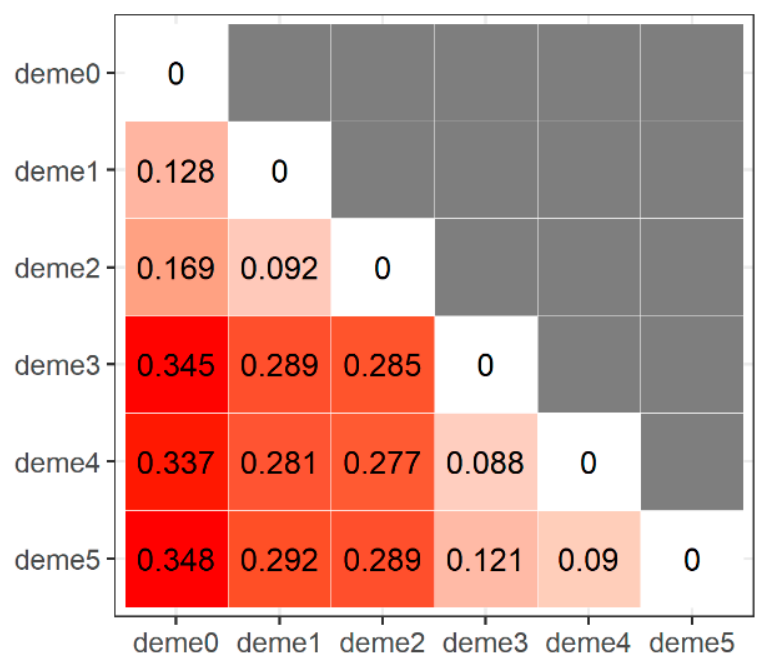

generation time $=40$

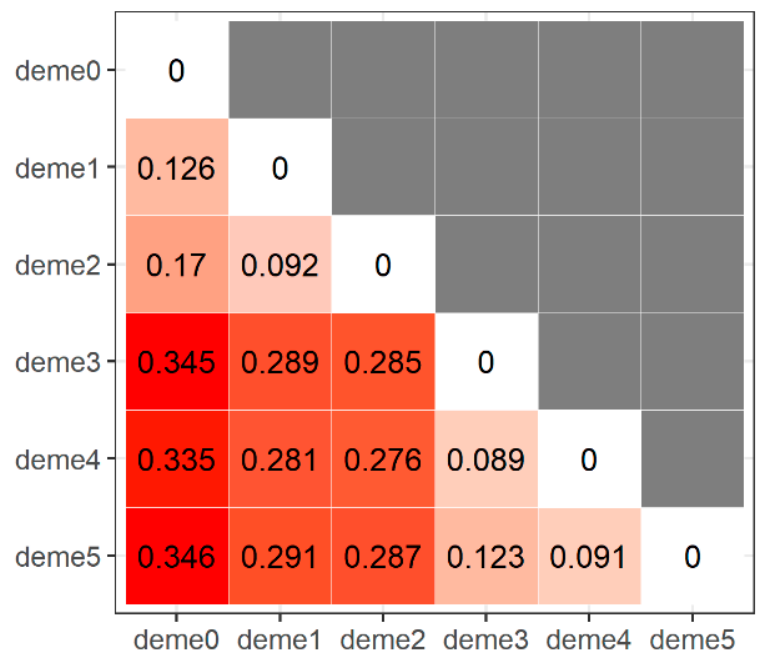

Figure A2. The mean pairwise Fst values calculated across 100 replicate simulations of a post-glacial faunal-mediated dispersal scenario ("fd + exp" in Table A1). This scenario of faunal dispersal assumes that deme0 was established by propagules from deme1 6kya, and a symmetric distance-weighted migration matrix. 


\section{post-megafauna isolation (60ky)}

generation time $=20$

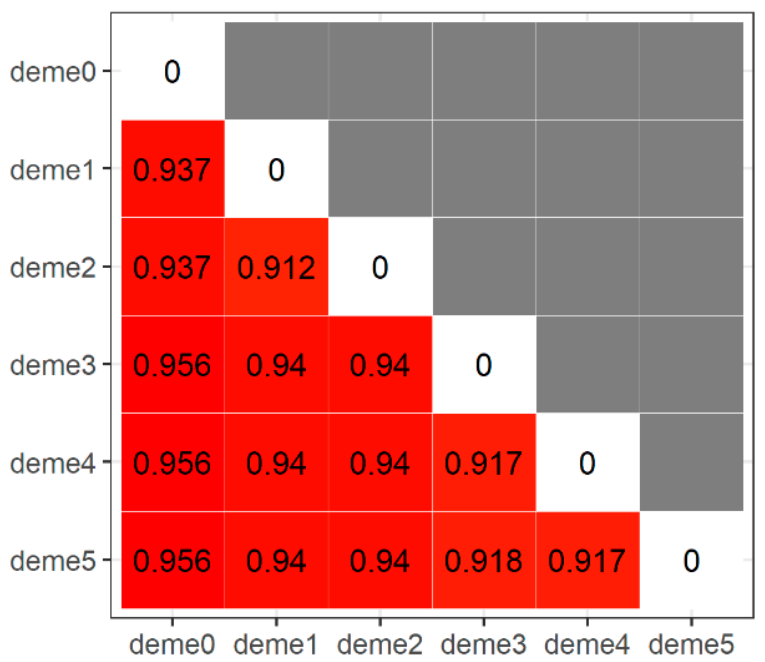

generation time $=40$

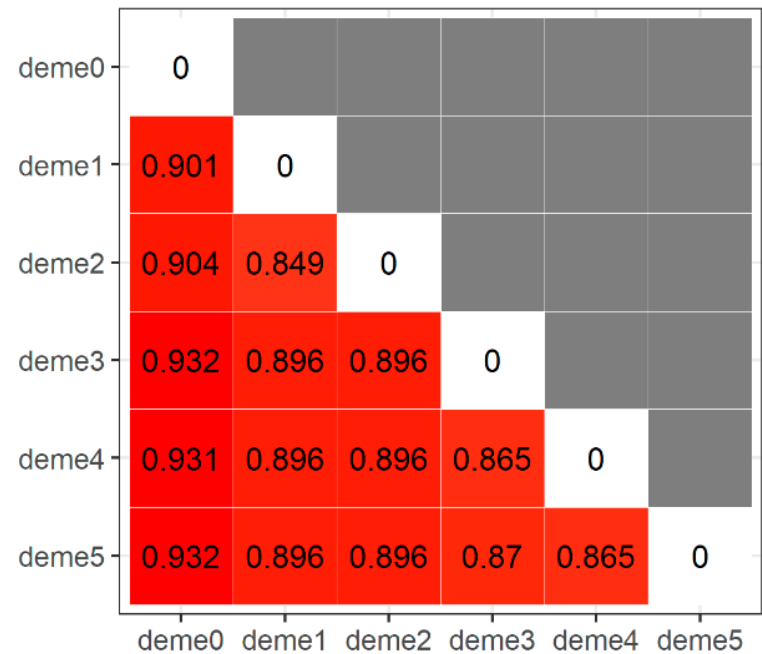

Figure A3. The mean pairwise Fst values calculated across 100 replicate simulations of a postmegafauna dispersal scenario ("nd" in Table A1). This dispersal scenario assumes that there has been no migration for 60,000 years (3500 or 1750 generations).

\section{human dispersal scenario 1}

generation time $=20$

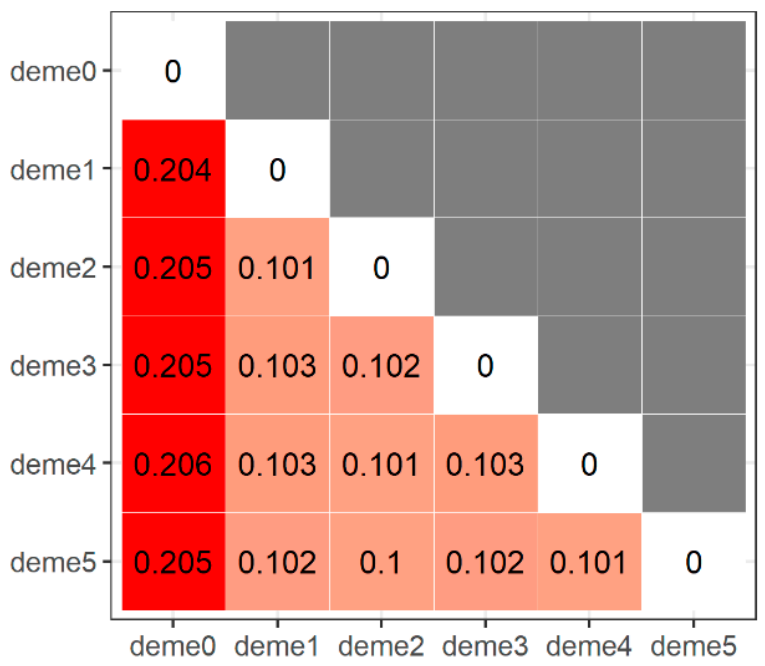

generation time $=40$

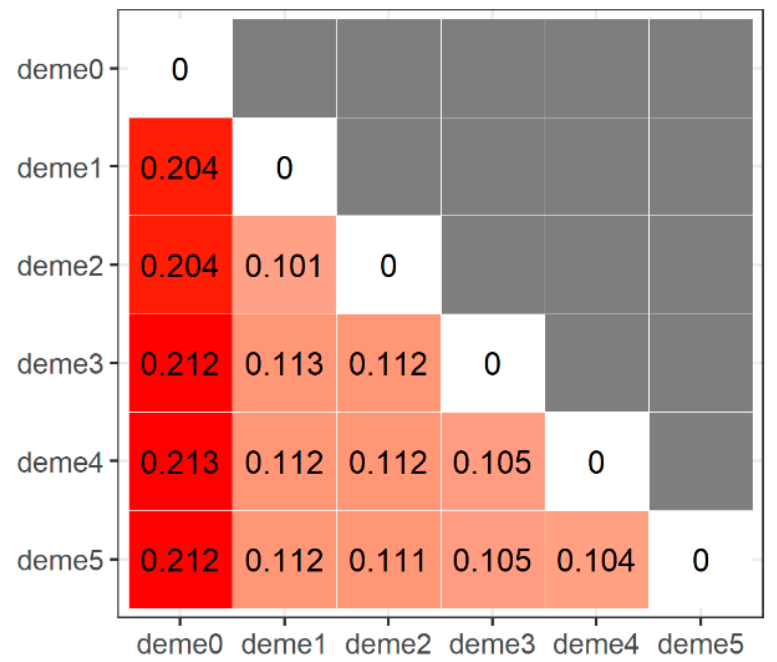

Figure A4. The mean pairwise Fst values calculated across 100 replicate simulations of a postmegafauna Indigenous-mediated dispersal scenario ("hd1" in Table A1). This scenario of Indigenous dispersal assumes a symmetric island model of migration between all demes from 5000-200 years ago. 


\section{human dispersal scenario 2}

generation time $=20$

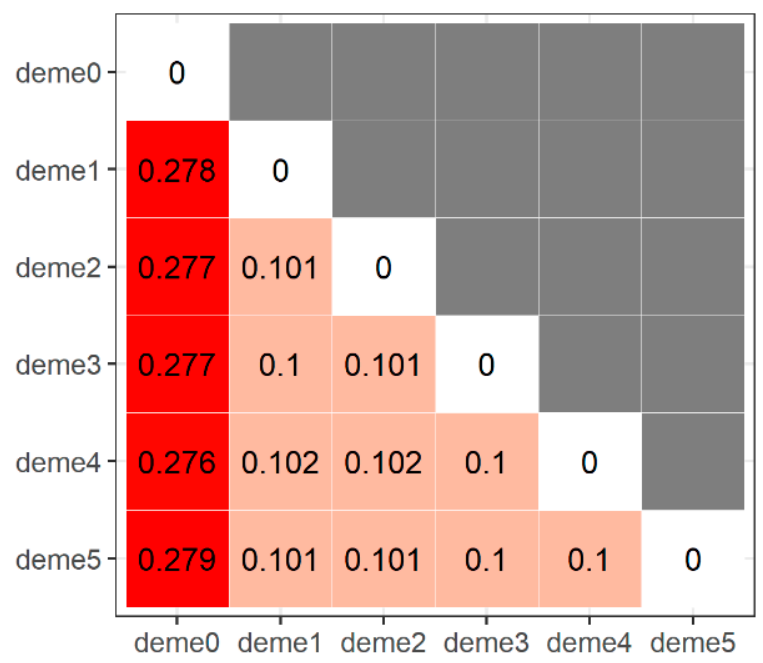

generation time $=40$

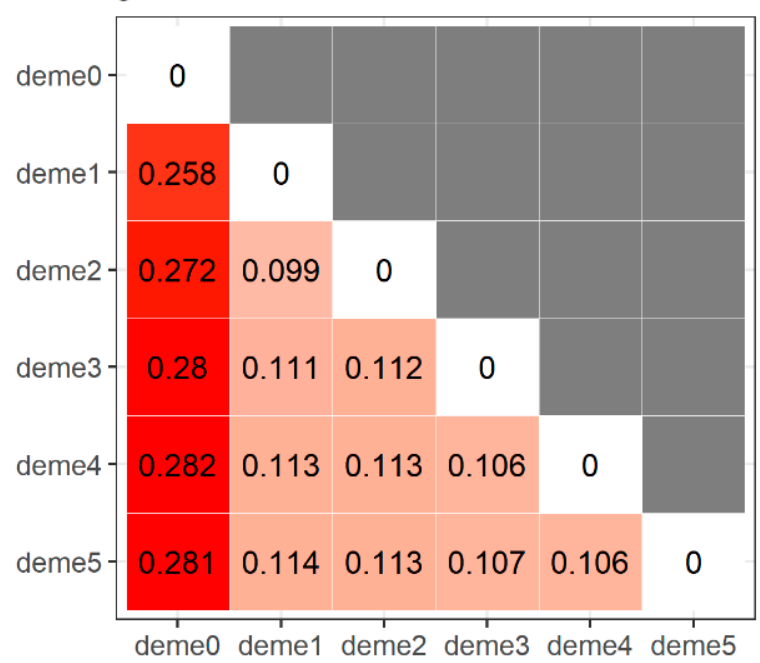

Figure A5. The mean pairwise Fst values calculated across 100 replicate simulations of a postmegafauna Indigenous-mediated dispersal scenario ("hd2" in Table A1). This scenario of Indigenous dispersal assumes that deme 0 was established by propagules from deme $15 \mathrm{kya}$, followed by a symmetric island model of migration between all demes between 5000-200 years ago.

\section{human dispersal scenario 3}

generation time $=20$

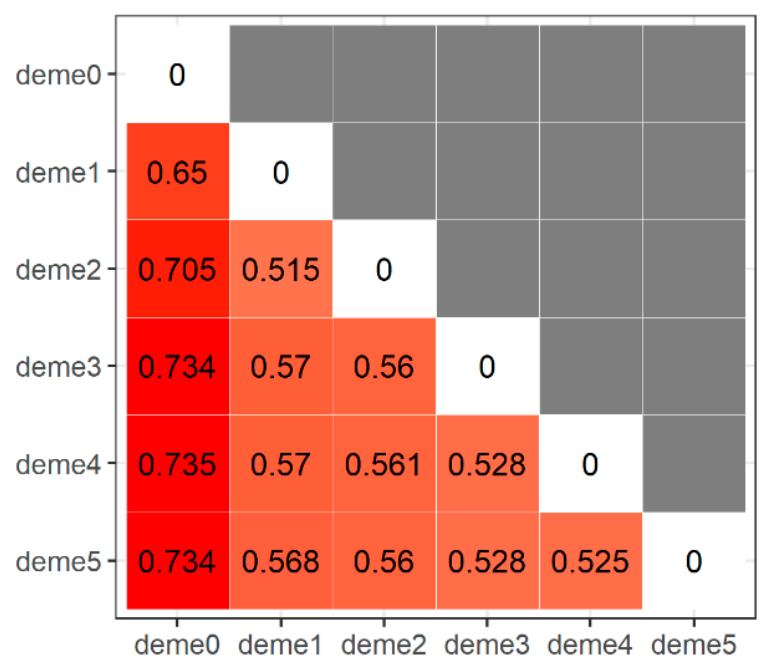

generation time $=40$

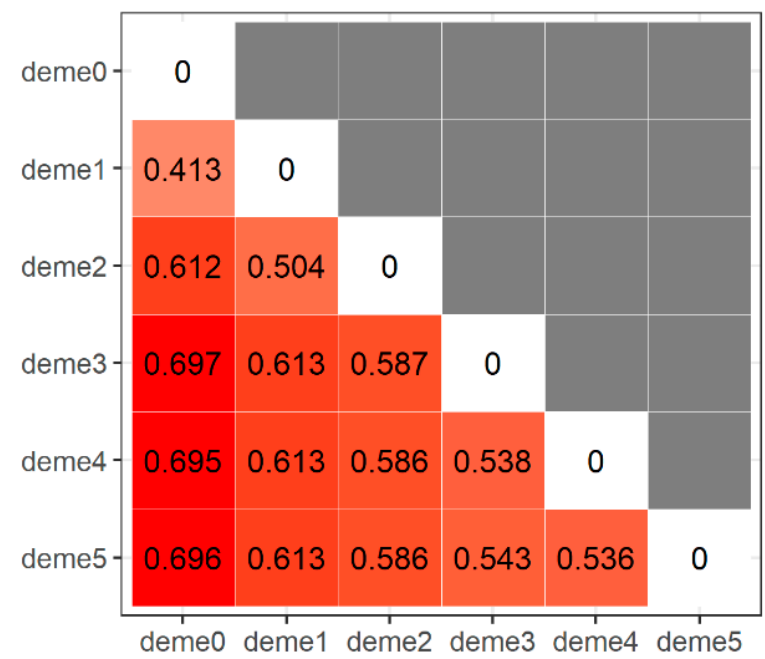

Figure A6. The mean pairwise Fst values calculated across 100 replicate simulations of a postmegafauna Indigenous-mediated dispersal scenario ("hd3" in Table A1). This scenario of Indigenous dispersal assumes that deme 0 was established by propagules from deme $15 \mathrm{kya}$, followed by a symmetric island model of migration between all demes between 5000-4000 years ago. 
human dispersal scenario 4

generation time $=20$

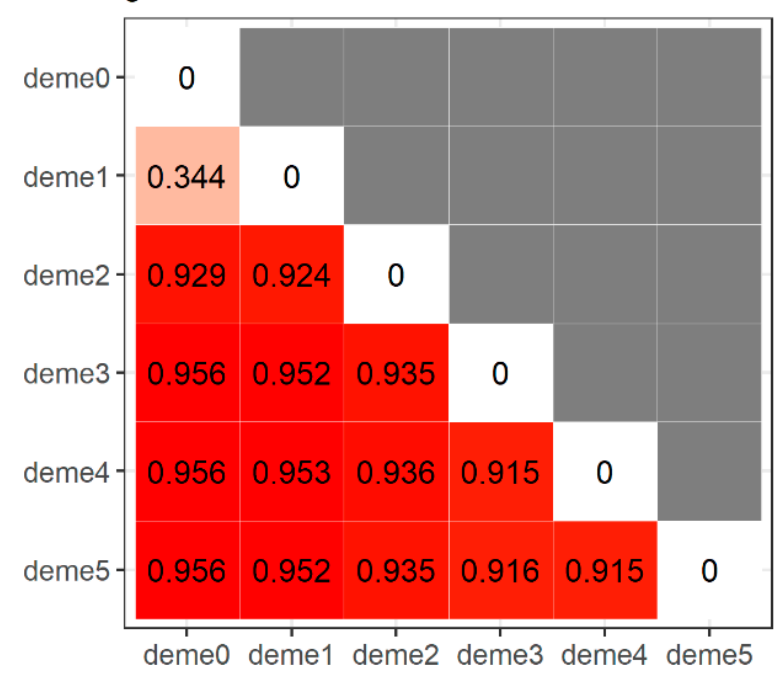

generation time $=40$

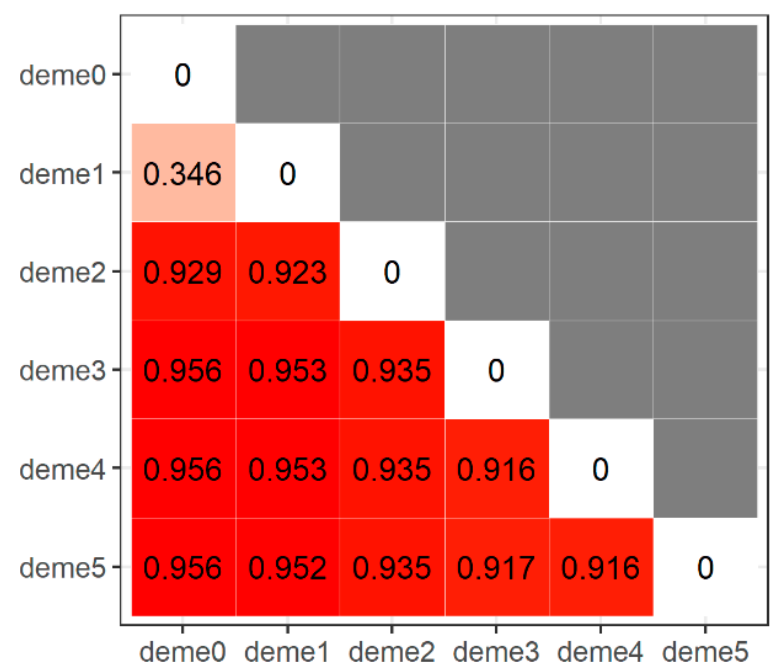

Figure A7. The mean pairwise Fst values calculated across 100 replicate simulations of a postmegafauna Indigenous-mediated dispersal scenario ("hd4" in Table A1). This scenario of Indigenous dispersal assumes that deme0 was established by propagules from deme1 $5 \mathrm{kya}$, with no further migration.

\section{human dispersal scenario 5}

generation time $=20$

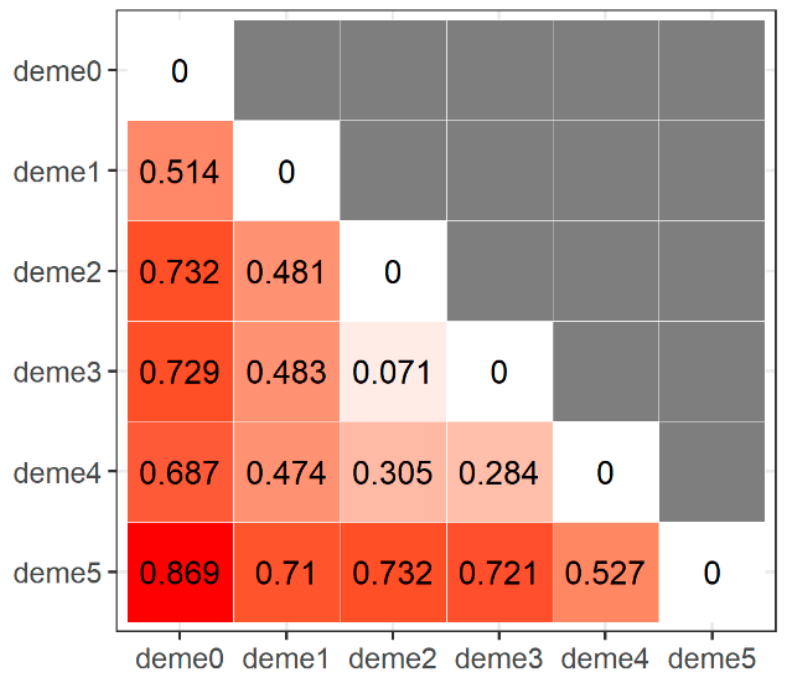

generation time $=40$

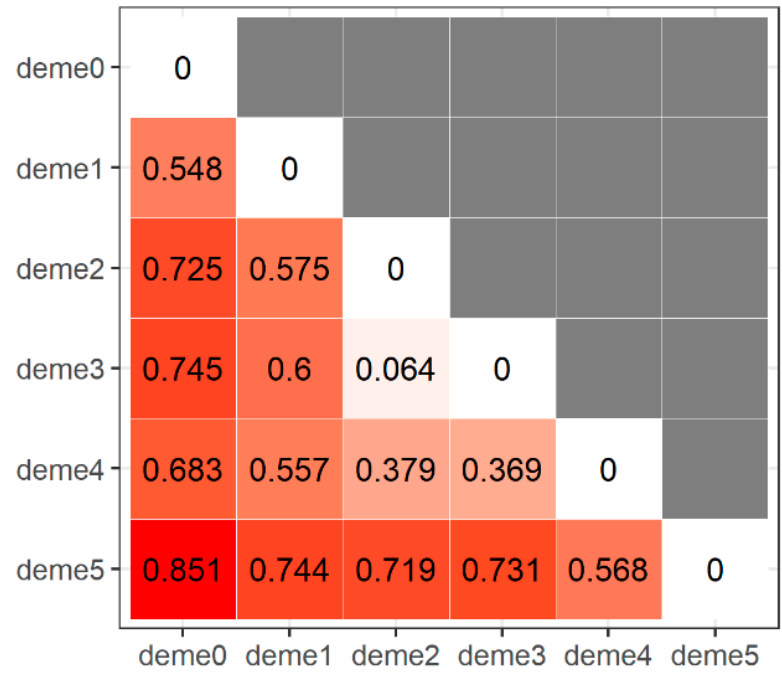

Figure A8. The mean pairwise Fst values calculated across 100 replicate simulations of a post-glacial faunal-mediated dispersal scenario ("hd5" in Table A1). This scenario of Indigenous dispersal assumes an asymmetric stepping-stone model of migration between 5000-200 years ago. 


\section{human dispersal scenario 6}

generation time $=20$

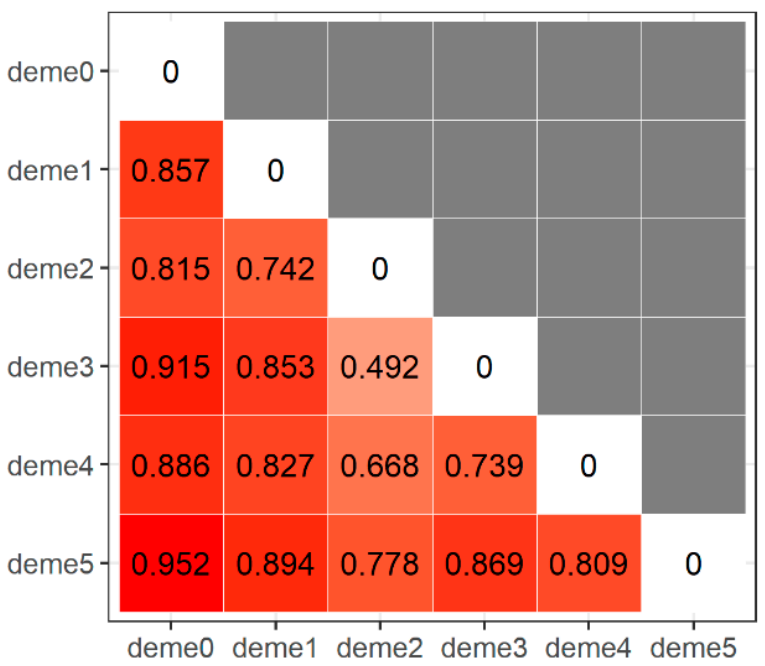

generation time $=40$

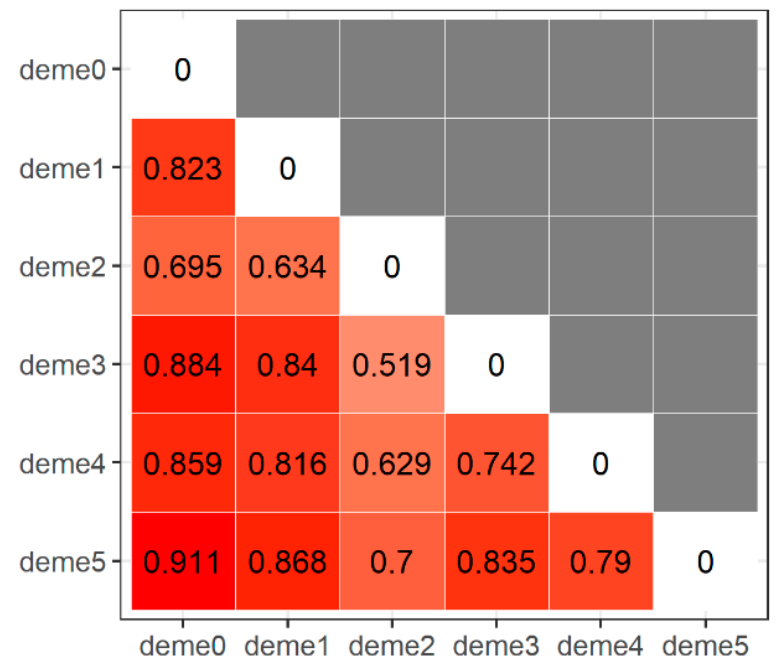

Figure A9. The mean pairwise Fst values calculated across 100 replicate simulations of a post-glacial faunal-mediated dispersal scenario ("hd6" in Table A1). This scenario of Indigenous dispersal assumes an asymmetric stepping-stone model of migration between 5000-4000 years ago.

\section{References}

1. Ens, E.; Walsh, F.; Clarke, P. Aboriginal People and Australia's Vegetation: Past and Current Interactions. In Australian Vegetation; Keith, D., Ed.; Cambridge University Press: Cambridge, UK, 2017.

2. Anderson, M.; Keeley, J. Native Peoples' Relationship to the California Chaparral. In Valuing Chaparral; Springer: Cham, Switzerland, 2018; pp. 79-121. ISBN 978-3-319-68302-7.

3. Anderson, M.K.; Rosenthal, J. An Ethnobiological Approach to Reconstructing Indigenous Fire Regimes in the Foothill Chaparral of the Western Sierra Nevada. J. Ethnobiol. 2015, 35, 4-36. [CrossRef]

4. $\quad$ Delcourt, P.A.; Delcourt, H.R.; Jones, E.L. Human Ecosystems in Eastern North America Since the Pleistocene; Cambridge University Press: Cambridge, UK, 2004.

5. Denham, T.; Donohue, M.; Booth, S. Horticultural experimentation in Northern Australia reconsidered. Antiquity 2009, 83, 634-648. [CrossRef]

6. Ross, N.J. Modern tree species composition reflects ancient Maya "forest gardens" in northwest Belize. Ecol. Appl. 2011, 21, 75-84. [CrossRef]

7. Abrams, M.D.; Nowacki, G.J. Native Americans as active and passive promoters of mast and fruit trees in the eastern USA. Holocene 2008, 18, 1123-1137. [CrossRef]

8. Gammage, B. The Biggest Estate on Earth: How Aborigines Made Australia; Allen \& Unwin: Crows Nest, NSW, Australia, 2011; ISBN 9781742377483.

9. Denham, T.; Atchison, J.; Austin, J.; Bestel, S.; Bowdery, D.; Crowther, A.; Dolby, N.; Fairbairn, A.; Field, J.; Kennedy, A.; et al. Archaeobotany in Australia and New Guinea: Practice, potential and prospects. Aust. Archaeol. 2009, 68, 1-10. [CrossRef]

10. Pascoe, B. Dark Emu; Magabala Books: Broome, WA, Australia, 2014; ISBN 9781921248016.

11. Hynes, R.A.; Chase, A.K. Plants, Sites and Domiculture: Aboriginal Influence upon Plant Communities in Cape York Peninsula. Archaeol. Ocean. 1982, 17, 38-50. [CrossRef]

12. Warren, R.J. Ghosts of Cultivation Past-Native American Dispersal Legacy Persists in Tree Distribution. PLoS ONE 2016, 11, e0150707. [CrossRef]

13. Silcock, J.L. Aboriginal Translocations: The Intentional Propagation and Dispersal of Plants in Aboriginal Australia. J. Ethnobiol. 2018, 28, 390-405. [CrossRef]

14. Loeb, R.E. Evidence of Prehistoric Corn (Zea mays) and Hickory (Carya spp.) Planting in New York City: Vegetation History of Hunter Island, Bronx County, New York. J. Torrey Bot. Soc. 1998, 125, 74-86. [CrossRef]

15. McLauchlan, K. Plant cultivation and forest clearance by prehistoric North Americans: Pollen evidence from Fort Ancient, Ohio, USA. Holocene 2003, 13, 557-566. [CrossRef]

16. Anderson, M.K. Tending the Wild: Native American Knowledge and the Management of California's Natural Resources; University of California Press: Oakland, CA, USA, 2005; ISBN 0520238567.

17. Hastorf, C.A. The Cultural Life of Early Domestic Plant Use. Antiquity 1998, 72, 773-782. [CrossRef]

18. Turner, N.J.; Ari, Y.; Berkes, F.; Davidson-Hunt, I.; Ertug, Z.F.; Miller, A. Cultural Management of Living Trees: An International Perspective. J. Ethnobiol. 2009, 29, 237-270. [CrossRef] 
19. Jezkova, T.; Jaeger, J.R.; Marshall, Z.L.; Riddle, B.R. Pleistocene impacts on the phylogeography of the Desert Pocket Mouse (Chaetodipus penicillatus). J. Mammal. 2009, 90, 306-320. [CrossRef]

20. Keener, C.; Kuhns, E. The Impact of Iroquoian Populations on the Northern Distribution of Pawpaws in the Northeast. N. Am. Archaeol. 2005, 18, 327-342. [CrossRef]

21. Bean, A.R. A new system for determining which plant species are indigenous in Australia. Aust. Syst. Bot. 2007, $20,1-43$. [CrossRef]

22. Ross, N.J.; Stevens, M.H.H.; Rupiper, A.W.; Harkreader, I.; Leben, L.A. The ecological side of an ethnobotanical coin: Legacies in historically managed trees. Am. J. Bot. 2014, 101, 1618-1630. [CrossRef]

23. Levis, C.; Costa, F.R.C.; Bongers, F.; Peña-Claros, M.; Clement, C.R.; Junqueira, A.B.; Neves, E.G.; Tamanaha, E.K.; Figueiredo, F.O.G.; Salomão, R.P.; et al. Persistent effects of pre-Columbian plant domestication on Amazonian forest composition. Science 2017, 355, 925-931. [CrossRef] [PubMed]

24. Clement, C.R.; de Cristo-Araújo, M.; d’Eeckenbrugge, G.C.; Pereira, A.A.; Picanço-Rodrigues, D. Origin and domestication of native Amazonian crops. Diversity 2010, 2, 72-106. [CrossRef]

25. Moreira, P.A.; Aguirre-Dugua, X.; Mariac, C.; Zekraoui, L.; Couderc, M.; Rodrigues, D.P.; Casas, A.; Clement, C.R.; Vigouroux, Y. Diversity of Treegourd (Crescentia cujete) Suggests Introduction and Prehistoric Dispersal Routes into Amazonia. Front. Ecol. Evol. 2017, 5, 150. [CrossRef]

26. Chaïr, H.; Traore, R.E.; Duval, M.F.; Rivallan, R.; Mukherjee, A.; Aboagye, L.M.; Van Rensburg, W.J.; Andrianavalona, V.; de Carvalho, M.A.A.P.; Saborio, F.; et al. Genetic Diversification and Dispersal of Taro (Colocasia esculenta (L.) Schott). PLoS ONE 2016, 11, e0157712. [CrossRef]

27. Hughes, C.E.; Govindarajulu, R.; Robertson, A.; Filer, D.L.; Harris, S.A.; Bailey, C.D. Serendipitous backyard hybridization and the origin of crops. Proc. Natl. Acad. Sci. USA 2007, 104, 14389-14394. [CrossRef] [PubMed]

28. Molina, J.; Sikora, M.; Garud, N.; Flowers, J.M.; Rubinstein, S.; Reynolds, A.; Huang, P.; Jackson, S.; Schaal, B.A.; Bustamante, C.D. Molecular evidence for a single evolutionary origin of domesticated rice. Proc. Natl. Acad. Sci. USA 2011, 108, 8351-8356. [CrossRef] [PubMed]

29. Pankin, A.; Altmüller, J.; Becker, C.; von Korff, M. Targeted resequencing reveals genomic signatures of barley domestication. New Phytol. 2018, 218, 1247-1259. [CrossRef] [PubMed]

30. Perrier, X.; De Langhe, E.; Donohue, M.; Lentfer, C.; Vrydaghs, L.; Bakry, F.; Carreel, F.; Hippolyte, I.; Horry, J.-P.; Jenny, C.; et al. Multidisciplinary perspectives on banana (Musa spp.) domestication. Proc. Natl. Acad. Sci. USA 2011, 108, 11311-11318. [CrossRef]

31. Lauterjung, M.B.; Bernardi, A.P.; Montagna, T.; Candido-Ribeiro, R.; da Costa, N.C.F.; Mantovani, A.; dos Reis, M.S. Phylogeography of Brazilian pine (Araucaria angustifolia): Integrative evidence for pre-Columbian anthropogenic dispersal. Tree Genet. Genomes 2018, 14, 1-12. [CrossRef]

32. Rossetto, M.; Ens, E.J.; Honings, T.; Wilson, P.D.; Yap, J.Y.S.; Costello, O.; Round, E.R.; Bowern, C. From Songlines to genomes: Prehistoric assisted migration of a rain forest tree by Australian Aboriginal people. PLoS ONE 2017, 12, e0186663. [CrossRef]

33. Tomimatsu, H.; Kephart, S.R.; Vellend, M. Phylogeography of Camassia quamash in western North America: Postglacial colonization and transport by indigenous peoples. Mol. Ecol. 2009, 18, 3918-3928. [CrossRef]

34. Lullfitz, A.; Byrne, M.; Knapp, L.; Hopper, S.D. Platysace (Apiaceae) of south-western Australia: Silent story tellers of an ancient human landscape. Biol. J. Linn. Soc. 2020, 130, 61-78. [CrossRef]

35. Rangan, H.; Bell, K.L.; Baum, D.A.; Fowler, R.; McConvell, P.; Saunders, T.; Spronck, S.; Kull, C.A.; Murphy, D.J. New genetic and linguistic analyses show ancient human influence on baobab evolution and distribution in Australia. PLoS ONE 2015, 10, e0119758. [CrossRef]

36. IUCN. Guidelines for Reintroductions and Other Conservation Translocations; IUCN: Gland, Switzerland, 2013.

37. Kerkhove, R. The Great Bunya Gathering: Early Accounts; Ray Kerkhove: Sydney, QLS, Australia, 2012.

38. Swan, D.K.; Deakin, U. Bunya Tukka Tracks: Investigating Traditional Travelling Routes of Eastern Australia. Master Thesis, Deakin University, Melbourne, VIC, Australia, 2017.

39. Cosgrove, R.; Field, J.; Ferrier, Å. The archaeology of Australia's tropical rainforests. Palaeogeogr. Palaeoclimatol. Palaeoecol. 2007, 251, 150-173. [CrossRef]

40. Jones, R.; Meehan, B. Plant Foods of the Gidjingali: Ethnographic and Archaeological Perspectives from Northern Australia on Tuber and Seed Exploitation. In Foraging and Farming: The Evolution of Plant Exploitation; Taylor \& Francis Group: Milton Park, UK, 1989; ISBN 9781317598299.

41. Rossetto, M.; Mcpherson, H.; Siow, J.; Kooyman, R.; van der Merwe, M.; Wilson, P.D. Where did all the trees come from? A novel multispecies approach reveals the impacts of biogeographical history and functional diversity on rain forest assembly. J. Biogeogr. 2015, 42, 2172-2186. [CrossRef]

42. Rossetto, M.; Kooyman, R.; Yap, J.Y.S.; Laffan, S.W. From ratites to rats: The size of fleshy fruits shapes species' distributions and continental rainforest assembly. Proc. R. Soc. B Biol. Sci. 2015, 282, 20151998. [CrossRef]

43. David, B.; Arnold, L.J.; Delannoy, J.J.; Fresløv, J.; Urwin, C.; Petchey, F.; McDowell, M.C.; Mullett, R.; Mialanes, J.; Wood, R.; et al. Late survival of megafauna refuted for Cloggs Cave, SE Australia: Implications for the Australian Late Pleistocene megafauna extinction debate. Quat. Sci. Rev. 2021, 253, 106781. [CrossRef] 
44. Graham, C.H.; Moritz, C.; Williams, S.E. Habitat history improves prediction of biodiversity in rainforest fauna. Proc. Natl. Acad. Sci. USA 2006, 103, 632-636. [CrossRef] [PubMed]

45. Kooyman, R.; Rossetto, M.; Cornwell, W.; Westoby, M. Phylogenetic tests of community assembly across regional to continental scales in tropical and subtropical rain forests. Glob. Ecol. Biogeogr. 2011, 20, 707-716. [CrossRef]

46. Mellick, R.; Lowe, A.; Rossetto, M. Consequences of long- and short-term fragmentation on the genetic diversity and differentiation of a late successional rainforest conifer. Aust. J. Bot. 2011, 59, 351-362. [CrossRef]

47. Fahey, M.; Rossetto, M.; Wilson, P.D.; Ho, S.Y.W. Habitat preference differentiates the Holocene range dynamics but not barrier effects on two sympatric, congeneric trees (Tristaniopsis, Myrtaceae). Heredity 2019, 123, 532-548. [CrossRef]

48. Moritz, C.; Hoskin, C.J.; MacKenzie, J.B.; Phillips, B.L.; Tonione, M.; Silva, N.; VanDerWal, J.; Williams, S.E.; Graham, C.H. Identification and dynamics of a cryptic suture zone in tropical rainforest. Proc. R. Soc. B Biol. Sci. 2009, 276, 1235-1244. [CrossRef]

49. Schneider, C.; Moritz, C. Rainforest Refugia and Evolution in Australia's Wet Tropics. Proc. Biol. Sci. 1999, 266, 191-196. [CrossRef]

50. Edwards, R.D.; Crisp, M.D.; Cook, D.H.; Cook, L.G. Congruent biogeographical disjunctions at a continent-wide scale: Quantifying and clarifying the role of biogeographic barriers in the Australian tropics. PLoS ONE 2017, 12, e0174812. [CrossRef]

51. Costion, C.M.; Lowe, A.J.; Rossetto, M.; Kooyman, R.M.; Breed, M.F.; Ford, A.; Crayn, D.M. Building a Plant DNA Barcode Reference Library for a Diverse Tropical Flora: An Example from Queensland, Australia. Diversity 2016, 8, 5. [CrossRef]

52. Metcalfe, D.J.; Ford, A.J. Floristics and Plant Biodiversity of the Rainforests of the Wet Tropics; Blackwell Publishing: Hoboken, NJ, USA, 2008

53. Heslewood, M.M.; Lowe, A.J.; Crayn, D.M.; Rossetto, M. Contrasting levels of connectivity and localised persistence characterise the latitudinal distribution of a wind-dispersed rainforest canopy tree. Genetica 2014, 142, 251-264. [CrossRef] [PubMed]

54. Elmouttie, D.; Mather, P.B. Can rodents enhance germination rates in rainforest seeds? Ecol. Manag. Restor. 2012, 13, 203-207. [CrossRef]

55. Hocknull, S.A.; Zhao, J.; Feng, Y.; Webb, G.E. Responses of Quaternary rainforest vertebrates to climate change in Australia. Earth Planet. Sci. Lett. 2007, 264, 317-331. [CrossRef]

56. Rossetto, M.; Crayn, D.; Ford, A.; Mellick, R.; Sommerville, K. The influence of environment and life-history traits on the distribution of genes and individuals: A comparative study of 11 rainforest trees. Mol. Ecol. 2009, 18, 1422-1438. [CrossRef]

57. Bradford, M.G.; Dennis, A.J.; Westcott, D.A. Diet and dietary preferences of the southern cassowary (Casuarius casuarius) in North Queensland, Australia. Biotropica 2008, 40, 338-343. [CrossRef]

58. Dennis, A.J.; Westcott, D.A. Reducing complexity when studying seed dispersal at community scales: A functional classification of vertebrate seed dispersers in tropical forests. Oecologia 2006, 149, 620-634. [CrossRef]

59. Clarke, P.A. Progress Report on the Anthropological Aspects of the Indigenous Plant Food Database; University of Adelaide: Adelaide, SA, Australia, 2018; Available online: https://theoranafoundation.org/projects/indigenous-food-database/ (accessed on 5 November 2021).

60. Maiden, J.H. The Useful Native Plants of Australia; Trubner: London, UK, 1889.

61. Roth, W.E. North Queensland Ethnography. In Food: Its Search, Capture, and Preparation; Home Secretary' Departmant: Brisbane, QLD, Australia, 1901; Volume 3.

62. Coyyan. The Aboriginals. In North Herreditary (The Tablelander); Columns I-X; National Library of Australia: Canberra, ACT, Australia, 1918.

63. Dixon, R.M.W. Searching for Aboriginal Languages: Memoirs of a Field Worker; Cambridge University Press: Cambridge, UK, 1983.

64. Birtles, T.G. Australia's Ever-Changing Forests III. In Proceedings of the Third National Conference on Australian Forest History, Jervis, NSW, Australia, 24-27 November 1996; Dargavel, J., Ed.; The Australian National University Press: Canberra, ACT, Australia, 1996; pp. 169-187.

65. Anderson, C. Traditional material culture of the Kuku-Yalanji of Bloomfield River, north Queensland. Rec. South Aust. Mus. 1996, $29,63-83$.

66. Ferrier, A.; Cosgrove, R. Aboriginal Exploitation of Toxic Nuts as a Late-Holocene Subsistence Strategy in Australia's Tropical Rainforests. In Peopled Landscapes: Archaeological and Biogeographic Approaches to Landscapes; ANU Press: Acton, ACT, Australia, 2018.

67. Maiden, J.H. Native food-plants. Agric. Gaz. N. S. W. 1900, 10, 117-130.

68. Low, T. Bush Tucker. In Australia's Wild Food Harvest; Angus \& Robertson: Sydney, QLS, Australia, 1989.

69. Field, J.; Cosgrove, R.; Fullagar, R.; Lance, B. Starch Residues on Grinding Stones in Private Collections: A Study of Morahs from the Tropical Rainforests of NE Queensland. In Archaeological Science under a Microscope: Studies in Residue and Ancient DNA Analysis in Honour of Thomas H. Loy; ANU Press: Sydney, QLS, Australia, 2009; pp. 103-120.

70. Cribb, A.B.; Cribb, J.W. Wild Food in Australia; Fontana/Collins: Sydney, QLS, Australia, 1982.

71. Ferrier, A. Journeys into the Rainforest. Archaeology of Culture Change and Continuity on the Evelyn Tableland, North Queensland, 43rd ed.; Board, T.A.E., Ed.; ANU Press: Sydney, QLS, Australia, 2015; ISBN 9781925022872.

72. Harris, D.R. The interplay of ethnographic and archaeological knowledge in the study of past human subsistence in the tropics. $J$. R. Anthropol. Inst. 2006, 12, S63-S78. [CrossRef]

73. Cherikoff, V.; Isaacs, J. The Bush Food Handbook: How to Gather, Grow, Process and Cook Australian Wild Foods; Ti Tree Press: Sydney, QLS, Australia, 1989.

74. Australia, G. Episode 28: Booderee Botanic Gardens; Australian Broadcasting Corporation: Sydney, QLS, Australia, 2014. 
75. Sansaloni, C.; Petroli, C.; Jaccoud, D.; Carling, J.; Detering, F.; Grattapaglia, D.; Kilian, A. Diversity Arrays Technology (DArT) and next-generation sequencing combined: Genome-wide, high throughput, highly informative genotyping for molecular breeding of Eucalyptus. BMC Proc. 2011, 5, 54. [CrossRef]

76. Coissac, E. A de Novo Assembler Dedicated to Organelle Genome Assembling. 2016. Available online: https//pypi.python.org/ pypi/ORG.asm/0.2.04 (accessed on 3 March 2021).

77. Tillich, M.; Lehwark, P.; Pellizzer, T.; Ulbricht-Jones, E.S.; Fischer, A.; Bock, R.; Greiner, S. GeSeq-Versatile and accurate annotation of organelle genomes. Nucleic Acids Res. 2017, 45, W6-W11. [CrossRef] [PubMed]

78. Bradburd, G.S.; Ralph, P.L.; Coop, G.M. Disentangling the effects of geographic and ecological isolation on genetic differentiation. Evolution 2013, 67, 3258-3273. [CrossRef] [PubMed]

79. Weir, B.S.; Hill, W.G. Estimating F-statistics. Annu. Rev. Genet. 2002, 36, 721-750. [CrossRef] [PubMed]

80. Oksanen, J.; Blanchet, F.G.; Friendly, M.; Kindt, R.; Legendre, P.; Mcglinn, D.; Minchin, P.R.; O’Hara, R.B.; Simpson, G.L.; Solymos, P.; et al. Package "vegan" Title Community Ecology Package. Community Ecol. Packag. 2019, 2, 1-295.

81. Frichot, E.; Mathieu, F.; Trouillon, T.; Bouchard, G.; François, O. Fast and efficient estimation of individual ancestry coefficients. Genetics 2014, 196, 973-983. [CrossRef]

82. Lawson, D.J.; van Dorp, L.; Falush, D. A tutorial on how not to over-interpret Structure and Admixture bar plots. Nat. Commun. 2018, 9, 1-11. [CrossRef]

83. Leigh, J.W.; Bryant, D. Popart: Full-feature software for haplotype network construction. Methods Ecol. Evol. 2015, 9, 1110-1116. [CrossRef]

84. Hopkins, M.S.; Graham, A.W. The viability of seeds of rainforest species after experimental soil burials under tropical wet lowland forest in north-eastern Australia. Aust. J. Ecol. 1987, 12, 97-108. [CrossRef]

85. Excoffier, L.; Dupanloup, I.; Huerta-Sánchez, E.; Foll, M. Robust demographic inference from genomic and SNP data. PLoS Genet. 2013, 9, e1003905. [CrossRef]

86. Excoffier, L.; Marchi, N.; Marques, D.A.; Matthey-Doret, R.; Gouy, A.; Sousa, V.C. fastsimcoal2: Demographic inference under complex evolutionary scenarios. Bioinformatics 2021, 37, 4882-4885. [CrossRef] [PubMed]

87. Excoffier, L.; Lischer, H.E.L. Arlequin suite ver 3.5: A new series of programs to perform population genetics analyses under Linux and Windows. Mol. Ecol. Resour. 2010, 10, 564-567. [CrossRef] [PubMed]

88. Rossetto, M.; Beaumont, L.; Das, S.; Yap, S. Bioclimatic Discordance: Combining Molecular and Environmental Data to Identify Floristic Refugia and Corridors. Final Report Prepared for the NSW Office of Environment and Heritage. April 2018, pp. 1-10. Available online: https://climatechange.environment.nsw.gov.au/. 